\title{
Observing ice clouds in the submillimeter spectral range: the CloudIce mission proposal for ESA's Earth Explorer 8
}

\author{
S. A. Buehler ${ }^{1}$, E. Defer ${ }^{2}$, F. Evans ${ }^{3}$, S. Eliasson ${ }^{1}$, J. Mendrok ${ }^{1}$, P. Eriksson ${ }^{4}$, C. Lee ${ }^{5}$, C. Jiménez ${ }^{2}$, C. Prigent ${ }^{2}$, \\ S. Crewell ${ }^{6}$, Y. Kasai ${ }^{7}$, R. Bennartz ${ }^{8}$, and A. J. Gasiewski ${ }^{9}$ \\ ${ }^{1}$ Division of Space Technology, Department of Computer Science, Electrical and Space Engineering, \\ Luleå University of Technology, Kiruna, Sweden \\ ${ }^{2}$ CNRS, Laboratoire d'Etudes du Rayonnement et de la Matière en Astrophysique, Observatoire de Paris, Paris, France \\ ${ }^{3}$ Department of Atmospheric and Oceanic Sciences, University of Colorado, Boulder, USA \\ ${ }^{4}$ Department of Earth and Space Sciences, Chalmers University of Technology, Gothenburg, Sweden \\ ${ }^{5}$ Met Office, Exeter, UK \\ ${ }^{6}$ Institute for Geophysics and Meteorology, University of Cologne, Cologne, Germany \\ ${ }^{7}$ National Institute of Information and Communications Technology (NICT), Tokyo, Japan \\ ${ }^{8}$ Atmospheric and Oceanic Sciences, University of Wisconsin, Madison, USA \\ ${ }^{9}$ NOAA-CU Center for Environmental Technology (CET), Department of Electrical and Computer Engineering, \\ University of Colorado at Boulder, Boulder, USA
}

Correspondence to: S. A. Buehler (sbuehler@ltu.se)

Received: 14 October 2011 - Published in Atmos. Meas. Tech. Discuss.: 6 February 2012

Revised: 24 May 2012 - Accepted: 8 June 2012 - Published: 6 July 2012

\begin{abstract}
Passive submillimeter-wave sensors are a way to obtain urgently needed global data on ice clouds, particularly on the so far poorly characterized "essential climate variable" ice water path (IWP) and on ice particle size. CloudIce was a mission proposal to the European Space Agency ESA in response to the call for Earth Explorer 8 (EE8), which ran in 2009/2010. It proposed a passive submillimeter-wave sensor with channels ranging from $183 \mathrm{GHz}$ to $664 \mathrm{GHz}$. The article describes the CloudIce mission proposal, with particular emphasis on describing the algorithms for the data-analysis of submillimeter-wave cloud ice data (retrieval algorithms) and demonstrating their maturity. It is shown that we have a robust understanding of the radiative properties of cloud ice in the millimeter/submillimeter spectral range, and that we have a proven toolbox of retrieval algorithms to work with these data. Although the mission was not selected for EE8, the concept will be useful as a reference for other future mission proposals.
\end{abstract}

\section{Introduction}

Missing data on cloud ice water path (IWP) is a major gap in the current global climate observing system. To address this issue, the CloudIce mission proposal was presented to the European Space Agency ESA in the year 2010, in response to the call for Earth Explorer 8 (EE8). It proposed to measure properties of ice clouds, such as IWP, with a passive submillimeter-wave sensor with channels ranging from $183 \mathrm{GHz}$ to $664 \mathrm{GHz}$.

Some core parameters of the proposed mission and instrument are summarized in Table 1 . The intention with this table is to give the reader that is already familiar with the subject a quick overview. The mission and instrument requirements are properly discussed later (in Sects. 2 and 3).

The proposal narrowly missed being selected for Phase A. Several related activities are presently ongoing. One example is the development of a similar airborne instrument (ISMAR) at the Met Office (UK). Another example is the ICI candidate mission for MetOp-SG, which, as CloudIce, adopted many 
Table 1. An overview of some core parameters of CloudIce. For more detailed information see Tables 3 and 4.

\begin{tabular}{ll}
\hline Orbit & Sun-synchronous, tandem with MetOp \\
Viewing Geometry & Conical scan with $53.5^{\circ}$ ground incidence angle \\
Pixel size & $\approx 15 \mathrm{~km}$ with continuous coverage \\
Swath width & $\approx 1500 \mathrm{~km}$ \\
Channel frequency positions & $183.31 \pm 0.2,1.0,3.0,5.0,7.0,11.0 \mathrm{GHz}$ \\
& $243.20 \pm 2.5 \mathrm{GHz}$ \\
& $325.15 \pm 1.5,3.5,9.5 \mathrm{GHz}$ \\
& $448.00 \pm 1.4,3.0,7.2 \mathrm{GHz}$ \\
& $664.00 \pm 4.2 \mathrm{GHz}$ \\
Channel noise $(\mathrm{Ne} \Delta T)$ & $1-2 \mathrm{~K}$ \\
\hline
\end{tabular}

features from the general submillimeter-wave cloud ice mission concept documented in Buehler et al. (2007). Related missions are also under discussion in Japan and in the US.

For these ongoing activities, we perceive a need to document the scientific content of the proposal in a form that is more openly accessible (and citable) than the proposal itself. This article attempts to satisfy that need. Its content is mainly from the EE8 proposal, but we have removed idiosyncrasies that were due to formal requirements from ESA. Furthermore, the content was restructured, and those parts that can already be found in the open literature were removed or drastically shortened.

The article is structured as follows: Sect. 2 introduces scientific objectives and requirements, followed by Sect. 3, which discusses observation technique and technical requirements. Section 4, the longest section, discusses the different CloudIce data products and their retrieval algorithms, including available demonstrations. Finally, Sect. 5 presents summary and conclusions.

\section{Scientific objectives and requirements}

\subsection{Importance of cloud ice measurements}

Clouds play a crucial role for the climate on planet Earth. They are also a major source of uncertainty in climate predictions, as affirmed by the most recent fourth assessment report by the Intergovernmental Panel on Climate Change IPCC (Solomon et al., 2007).

Particularly large uncertainties are associated with those clouds that consist partly or entirely of ice particles (e.g. Stephens et al., 1990; Wendisch et al. , 2005; Penner, 2004). The microphysical formation mechanisms of cloud ice particles are less well understood than those of liquid droplets. Also, ice particle shapes and physical properties vary widely, complicating their interaction with radiation.

At the same time, there is a lack of reliable global measurements of cloud ice for climate model evaluation. As a consequence, different climate models exhibit large discrepancies in their cloud ice water content fields (Waliser et al., 2009, 2011; Eliasson et al., 2011). For example, as shown in Fig. 3 in Eliasson et al. (2011), the annual zonal mean ice water path (IWP) at $60^{\circ} \mathrm{N}$ ranges from approximately 15 to approximately $400 \mathrm{~g} \mathrm{~m}^{-2}$ for the climate models that participated in the fourth assessment of the IPCC. Even if one extremely high model, AR4-GISS, is removed, the range is still up to approximately $100 \mathrm{~g} \mathrm{~m}^{-2}$, almost an order of magnitude.

The existing space-based measurement capabilities, mostly by infrared and visible instruments, provide important information on the radiation effect of ice clouds. However, with the exception of radar measurements, which are discussed below, it is inherently difficult to relate these measurements to the bulk mass of ice, which is a basic climate model parameter, the parameter that can be linked to other stages of the water cycle by the requirement of total water mass continuity. Figure 2 in Eliasson et al. (2011) demonstrates this point, it shows that the zonal mean IWP at $60^{\circ} \mathrm{N}$ ranges from approximately 50 to approximately $150 \mathrm{~g} \mathrm{~m}^{-2}$ for the publicly available radar, IR, and visible data sets, and that discrepancies in the tropics are even stronger. We therefore argue that there is a particular need for cloud ice mass measurements.

The need for ice mass measurements is demonstrated for example by a recent study by Mitchell et al. (2008), who emphasize the importance of ice particle fall speed in global circulation model (GCM) simulations and conclude that, since fall speeds depend on particle mass and cross-sectional area, these properties must be better characterized for cirrus clouds.

This has also been recognized by the World Meteorological Organization (WMO), which classifies the total column of cloud ice (also called ice water path, IWP) as one of the essential climate variables (ECV) in the framework of the Global Climate Observing System (GCOS) (WMO, 2006).

Infrared measurements can provide IWP data and particle size information for relatively thin cirrus clouds (Stubenrauch, 2004), but not for IWP exceeding approximately $100 \mathrm{~g} \mathrm{~m}^{-2}$ (see Fig. 3.6 in above publication). 

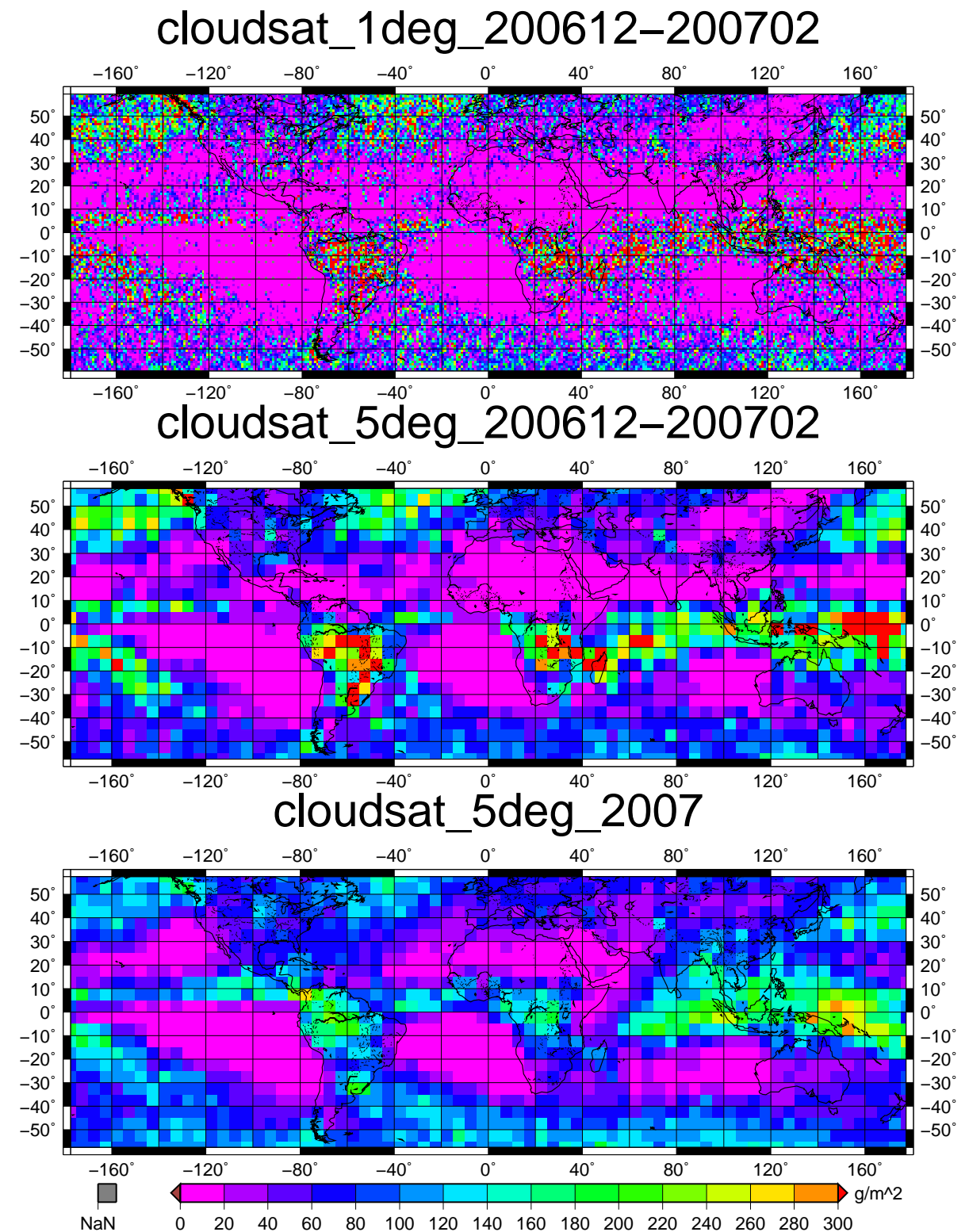

Fig. 1. An IWP climatology from CloudSat data. Top panel: seasonal climatology (winter 2006/2007) at $1^{\circ}$ spatial resolution. Middle panel: same seasonal climatology at $5^{\circ}$ resolution. Bottom panel: yearly climatology (2007) at $5^{\circ}$ resolution.

\subsection{Advantages of submillimeter sensors}

Active radar systems and passive millimeter/submillimeter instruments provide data that are directly related to the bulk mass of ice in an ice cloud. The two techniques are highly complementary. Radars, such as the CPR instruments of CloudSat and EarthCARE, provide high vertical resolution at the cost of poor horizontal coverage. Their main measurement uncertainties for ice mass are connected to unavoidable assumptions on the particle size distribution, assumptions on the radar signal attenuation in thicker clouds, and assumptions on the partitioning between liquid droplets and ice particles. A very useful analysis of the accuracy of different radar based ice water content (IWC) retrieval algorithms has been carried out by Heymsfield et al. (2008), using in-situ aircraft data and simulated radar data. According to Waliser et al. (2009), the Heymsfield et al. (2008) results imply an approximately $40 \%$ uncertainty for the actual CLOUDSAT radar-only IWC retrievals.

Figure 1 illustrates the horizontal coverage for radar data. It shows CloudSat IWP climatologies for different time periods and grid resolutions. Quite long time periods and quite coarse grid resolutions are necessary to bring down the sampling error (the "noise" in the images) to an acceptable level. The reason for this is that the radar samples only directly below the satellite and does not do any horizontal scanning. 
Table 2. Scientific mission requirements for a passive submillimeter-wave cloud ice mission, derived from breakthrough ranges in the pure scientific requirements for cloud ice observation. See Table 5 for parameter definitions. Delay requirements refer to numerical weather prediction (NWP) applications, since for climate and GCM validation/development applications the delay is not critical. The accuracy requirement for IWP is the maximum of relative accuracy and threshold for each IWP value. The horizontal resolution requirement assumes continuous coverage, which requires an appropriate footprint overlap. The table is an expanded version of Table 4 in Buehler et al. (2007) with more detailed comments. The requirement numbers themselves are identical.

\begin{tabular}{|c|c|c|}
\hline Parameter & $\begin{array}{l}\text { Requirement } \\
\text { [target-threshold] }\end{array}$ & Remark \\
\hline IWP accuracy & $\begin{array}{l}10-50 \% \text { relative, } \\
\text { with } 1-10 \mathrm{~g} \mathrm{~m}^{-2} \text { threshold }\end{array}$ & The total vertical column of cloud ice. \\
\hline Zme accuracy & $100-500 \mathrm{~m}$ & $\begin{array}{l}\text { The median IWP altitude, } \\
\text { representative for the altitude where } \\
\text { most of the cloud mass is located. }\end{array}$ \\
\hline Dme accuracy & $10-50 \mu \mathrm{m}$ & $\begin{array}{l}\text { The median mass equivalent sphere } \\
\text { diameter, a size parameter related } \\
\text { to the particle mass, not the } \\
\text { cross-section. }\end{array}$ \\
\hline Spatial coverage & Global/near global & For global climate model evaluation. \\
\hline Horizontal resolution & $5-20 \mathrm{~km}$ & Assuming continuous coverage. \\
\hline Diurnal sampling & Fixed local time $( \pm 0.5 \mathrm{~h})$ & To avoid aliasing of the diurnal cycle. \\
\hline Observation cycle & $6-24 \mathrm{~h}$ & $\begin{array}{l}\text { At least one measurement per day, } \\
\text { in order to derive monthly } \\
\text { climatologies. }\end{array}$ \\
\hline Delay & $1-4 h$ & For NWP. \\
\hline Observation time period & $7-1$ years & Goal is one ENSO cycle. \\
\hline
\end{tabular}

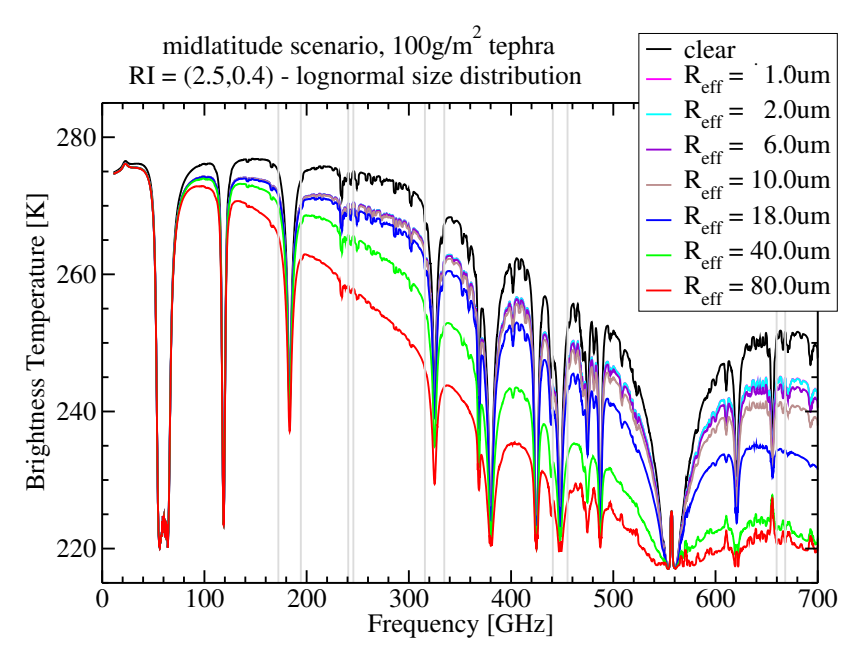

Fig. 2. Brightness temperature spectrum for a total column ash content of $100 \mathrm{~g} \mathrm{~m}^{-2}$, an assumed refractive index of $2.5+0.4 \mathrm{i}$, and spherical particles with log-normal size distributions of different effective radius.

Another way to express this is to note that CloudSat measurements cover an area of roughly $12 \mathrm{~km}^{2} \mathrm{~s}^{-1}$, whereas CloudIce measurements would cover an area of roughly $10000 \mathrm{~km}^{2} \mathrm{~s}^{-1}$.
Passive millimeter/submillimeter sensors can provide continuous near-global coverage on a daily basis, at the cost of a poor vertical resolution. If suitable frequencies are chosen, these measurements sample different parts of the ice particle size spectrum. The reason for this is that high frequencies interact more strongly with small particles, whereas low frequencies interact more strongly with large particles (see Fig. 3 of Buehler et al., 2007). A combination of channels at different frequencies therefore allows an estimation of the particle size, and thus also a more accurate estimation of the total ice mass.

\subsection{Scientific requirements}

Scientific requirements for submillimeter-wave satellite observations of cloud ice were examined in the context of four recent ESA studies (Charlton et al., 2002; Golding and Atkinson, 2002; Sreerekha et al., 2006; Jarret et al., 2007). The last of these studies attempted a synthesis of all available earlier results. It is summarized in an article by Buehler et al. (2007). Here, we just briefly summarize this last assessment, and refer to the article for details.

The core parameters of a submillimeter cloud ice mission would be the vertically integrated mass of ice in the atmosphere (IWP), a measure of the cloud altitude (Zme), and a measure of the ice particle size (Dme). In contrast to infrared 

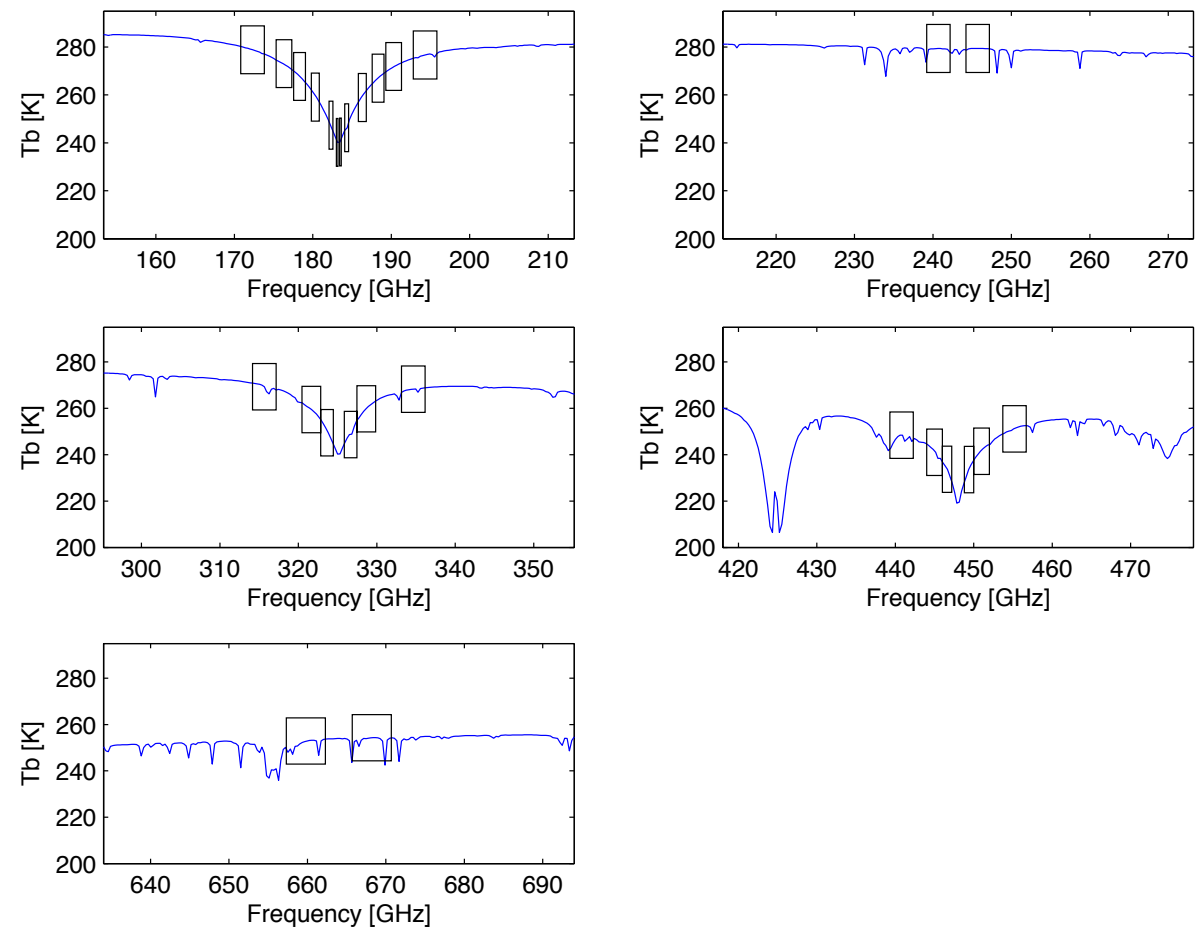

Fig. 3. A detailed view of the CloudIce channel positions. The spectrum shown is the simulated clear-sky radiance (in Planck brightness temperature units) for a tropical model atmosphere. Each channel consists of two sidebands, located on either side of a central frequency. The heterodyne technique used implies that only a single measurement value is recorded for the integrated radiance in both sidebands. The atmospheric scenario is from Anderson et al. (1986).

instruments, both Zme and Dme are linked to the ice particle mass rather than other modes of the size distribution. We define Zme as the altitude where IWP has reached half of its total column value. Similarly, we define Dme as the particle size for which half of the total mass is in smaller particles (and the other half is in larger particles).

The process of deriving scientific mission requirements involved several steps. As a first step, a table of pure scientific requirements for cloud ice observations was compiled. Sources for this table were the CEOS/WMO requirement database (Hinsman, 2003), the earlier ESA studies, and an independent new requirement analysis structured by parameter and application. Since cloud ice is currently not well covered by the global observing system, the range between threshold and target in the pure scientific requirement table is large for most parameters. The pure scientific requirement table is therefore not suitable for mission sizing.

In a second step, the concept of breakthrough ranges was used to narrow down the requirements from the pure science table. The breakthrough range is the sub-range between threshold and target in the pure scientific requirements where there is a particularly steep increase of benefit with increasing cost. It is therefore very suitable for mission sizing. The result of this analysis is summarized in Table 2.

Buehler et al. (2007) contains detailed justifications for the numbers in Table 2, which we do not want to repeat here.
Instead we broadly outline below what considerations influence the different requirements.

The accuracy requirements for IWP, Zme, and Dme are influenced by the need for model evaluation, but also by comparison to existing sensors. The requirement for near global coverage comes from the need to evaluate and improve global circulation models. The horizontal resolution requirement comes from the typical resolution of mesoscale circulation models, an appropriate scale to represent clouds globally by the time of the mission launch.

Concerning the local time of the measurements, two different scientific mission scenarios are conceivable: (a) a mission focusing on obtaining global climatologies with good horizontal and temporal resolution, or (b) a mission focussing on diurnal cycles. The two scenarios exclude each other technically (not scientifically), because (a) calls for a sun-synchronous orbit, whereas (b) calls for a non sunsynchronous orbit, where the local time drifts from overpass to overpass. The disadvantage of such an orbit is that larger averaging intervalls in time and space would be needed to derive climatologies. For CloudIce, it was decided to concentrate on scenario (a).

The observation cycle requirement (once to several times per day) comes from the need to derive monthly or seasonal climatologies with reasonable temporal sampling (the monthly mean value should be an average of individual 
measurements on many different days). The delay requirement comes from operational weather forecasting. Lastly, the observation time (mission lifetime) requirement comes from the need to observe several different annual cycles (preferably one entire ENSO cycle) in order to capture at least some of the natural variability of the atmosphere.

Beside the scientific requirements for the CloudIce mission itself, there is a more general scientific requirement for an airborne companion instrument. In the mission preparation phase this can be used for algorithm development and test/validation. During the flight of CloudIce, it can be used for validation. The airborne instrument should participate in campaigns where synergistic measurements with other cloud sensors can be made. A good example for the usefulness of an airborne instrument in both mission phases is MIPAS, the Michelson Interferometer for Passive Atmospheric Sounding (Fischer et al., 2008), and its aircraft and balloon companion instruments. (See also Sect. 4.3 with example aircraft data.)

\subsection{Summary of mission objectives}

CloudIce, or a similar mission, can deliver urgently needed global data on ice clouds, particularly on the so far poorly characterized "essential climate variable" ice water path (IWP) and on the characteristic cloud ice particle size.

It can deliver data with near global spatial coverage every $24 \mathrm{~h}$, and on a spatial scale consistent with future global climate models, to both evaluate and improve the models.

It can also demonstrate the benefit of submillimeter observations for precipitation retrieval, an important step towards a possible future deployment of submillimeter radiometers in a geostationary precipitation mission.

\section{Observation technique and technical requirements}

\subsection{Observation technique}

The technique of using passive submillimeter-wave measurements to retrieve cloud ice water content and ice particle size is based on two principles: Firstly, ice clouds reduce the upwelling thermal radiation in the submillimeter wavelength range, because they scatter some of it away in other directions. The brightness temperature depression is directly related to the amount of cloud ice.

Secondly, the interaction between radiation and ice particles depends on the ratio between particle size and wavelength, so observations at a particular frequency are most sensitive to particles of a particular size. Thus, measurements at different frequencies can sample the particle size distribution.

The idea of passive submillimeter-wave cloud ice remote sensing was first suggested by Evans and Stephens (1995), and refined in subsequent publications (e.g. Evans and Stephens, 1995). Specifically for CloudIce, the technique and its scientific basis is described in detail in Buehler et al. (2007), therefore this information is not repeated here.

A new aspect for CloudIce, not mentioned in Buehler et al. (2007), is that measurements at submillimeter frequencies are not only sensitive to hydrometeors, but are also expected to be sensitive to volcanic "ash" particles to some extent. (Interest in this was triggered by the eruption of volcano Eyjafjallajökull on Iceland in spring 2010, which injected a large amount of ash particles into the atmosphere.)

A quick sensitivity study was carried out to assess this. Figure 2 shows some results of this study. The main sources of uncertainty in these simulations are what shape, size distribution, and refractive index to assume for the volcanic particles. We assumed spherical particles, with log-normal size distributions, and a refractive index of $2.5+0.4 \mathrm{i}$. These are educated guesses, based on available literature, for example Manabe et al. (1992) and Bredow et al. (1995).

The study shows that, as expected, the submillimeter measurements would not be sensitive enough to detect the small ash concentrations far away from the source that still pose an air traffic risk (below $1 \mathrm{~g} \mathrm{~m}^{-2}$ ). The strength of submillimeter measurements lies in the fact that they can penetrate the fresh ash plume close to the source (which will have comparatively large particles and a high mass content). This should allow an estimate of the amount of ash that is emitted. This idea has already been applied for SSM/I data by Delene et al. (1996) and is expected to work with higher accuracy for CloudIce data.

\subsection{Channel positions and radiometric requirements}

The channel configuration and noise characteristics of CloudIce are summarized in Table 3. An overview plot of where these channels are located, relative to the atmospheric spectrum, can be found in Buehler et al. (2007). Receivers are spread out over a wide frequency range in order to sample frequencies with different cloud particle single scattering properties. Most receivers have multiple channels centered on a common water vapor absorption line. This is shown in Fig. 3. Note that, where possible, the channels are placed such that they avoid ozone spectral lines. This is in order to minimize the unwanted influence of the ozone concentration on the measured radiances. For the $183 \mathrm{GHz}$ line, it was already shown in John and Buehler (2004) that this influence is not completely negligible.

Because of the varying distance from the line center, the different channels are associated with different atmospheric opacities and sample different altitudes in the atmosphere. A good way to visualize this is by calculating the clearsky temperature Jacobians, as shown in Fig. 4. The peaks of the Jacobians indicate the sounding altitude for the different channels.

Note that the sounding altitude depends on the atmospheric conditions. Figure 4 shows Jacobians for two opposite extremes, tropical conditions and subarctic-winter 

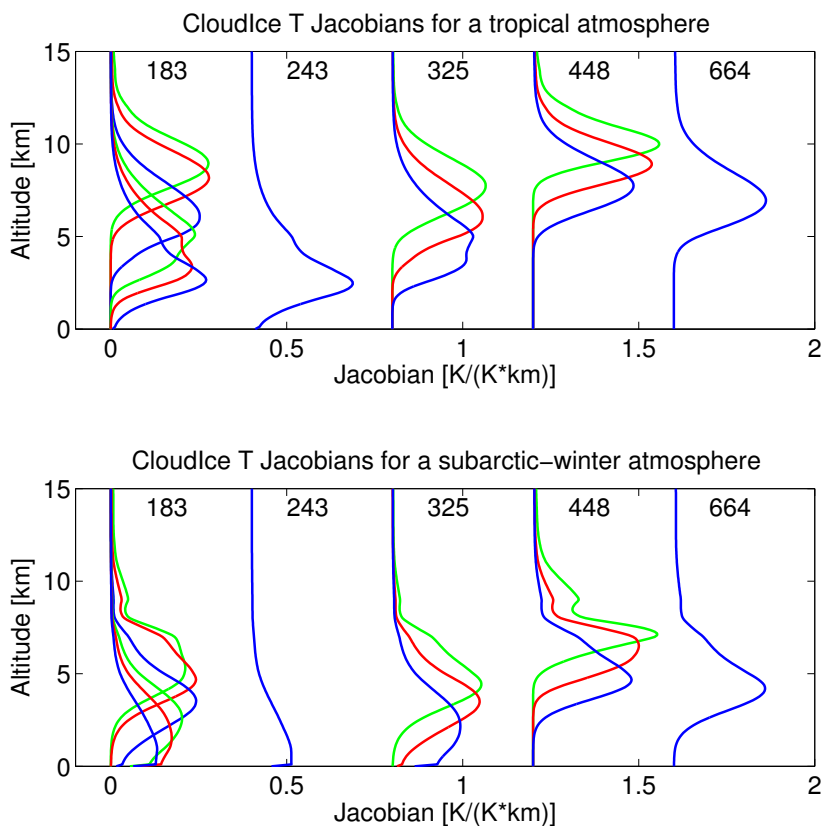

Fig. 4. CloudIce temperature Jacobians for a tropical atmosphere (top panel) and a subarctic-winter atmosphere (bottom panel). These are the derivatives of the measurement with respect to changes in the atmospheric temperature at different altitudes. The Jacobians indicate the measurement altitude of the different channels. Jacobians for different radiometers have been shifted to the right by different amounts, so that they all can be displayed in a single graph. The atmospheric scenarios are from Anderson et al. (1986). The assumed surface emissivity is 0.6.

conditions. Whereas all channels are sounding channels (with almost no surface influence) for tropical conditions, some channels see the surface for subarctic-winter conditions. This is the case for the three outermost $183 \mathrm{GHz}$ channels, for the channel at $243 \mathrm{GHz}$, and for the outermost $325 \mathrm{GHz}$ channel.

These channel characteristics are largely as proposed in Buehler et al. (2007), with the following modifications: Firstly, the $183 \mathrm{GHz}$ water vapor line, which was sampled with three channels in Buehler et al. (2007), is now sampled with six channels in order to extend the altitude range of that receiver. This change is partly motivated by technical heritage from the SAPHIR instrument on the Megha-Tropiques mission (Desbois et al., 2002).

Secondly, the receivers at 243 and $664 \mathrm{GHz}$ are proposed to be polarized in order to gather information on cloud particle asphericity and orientation (Prigent et al., 2001, 2005; Miao et al., 2003; Eriksson et al., 2011b).

The single-polarization channels should all be measuring in $\mathrm{V}$ polarization. There are two reasons for this. Firstly, and most importantly, simulations show that there is less uncertainty due to ice particle shape in the $\mathrm{V}$ signal, compared to the $\mathrm{H}$ signal. Secondly, since the incidence angle of CloudIce is close to the Brewster angle for water, the $\mathrm{V}$ polarization
Table 3. CloudIce channel specifications and radiometric requirements. $\mathrm{Ne} \Delta T$ is the random error in the measurement, due to radiometric noise. Abs. $\Delta T$ is the absolute error in the measurement.

\begin{tabular}{|c|c|c|c|c|c|c|}
\hline \# & $\begin{array}{c}\text { Center freq. } \\
\mathrm{GHz}\end{array}$ & $\begin{array}{r}\text { Freq. offset } \\
\mathrm{GHz}\end{array}$ & $\begin{array}{r}\text { Bandwidth } \\
\mathrm{MHz}\end{array}$ & Pol. & $\begin{array}{c}\mathrm{Ne} \Delta T \\
\mathrm{~K}\end{array}$ & $\begin{array}{c}\text { Abs. } \Delta T \\
\mathrm{~K}\end{array}$ \\
\hline 1 & 183.31 & 0.20 & 200 & V & 2.0 & 1 \\
\hline 2 & & 1.00 & 500 & V & 1.5 & 1 \\
\hline 3 & & 3.00 & 1000 & V & 1.0 & 1 \\
\hline 4 & & 5.00 & 1500 & V & 1.0 & 1 \\
\hline 5 & & 7.00 & 2000 & V & 1.0 & 1 \\
\hline 6 & & 11.00 & 3000 & V & 1.0 & 1 \\
\hline 7 & 243.20 & 2.50 & 3000 & V & 1.5 & 1 \\
\hline 8 & & & & $\mathrm{H}$ & & 1 \\
\hline 9 & 325.15 & 1.50 & 1600 & V & 1.5 & 1 \\
\hline 10 & & 3.50 & 2400 & V & 1.0 & 1 \\
\hline 11 & & 9.50 & 3000 & V & 1.0 & 1 \\
\hline 12 & 448.00 & 1.40 & 1200 & V & 2.0 & 1 \\
\hline 13 & & 3.00 & 2000 & V & 1.5 & 1 \\
\hline 14 & & 7.20 & 3000 & V & 1.5 & 1 \\
\hline 15 & 664.00 & 4.20 & 5000 & V & 1.5 & 1 \\
\hline 16 & & & & $\mathrm{H}$ & & 1 \\
\hline
\end{tabular}

results in a "warm" radiative background even under those conditions where some channels start to see the surface. This increases the contrast between the warm background and the cold scattering signature.

The requirements for radiometric precision and absolute accuracy (in Table 3) reflect our expectation of what is technologically feasible. Roughly similar figures have been used as input to the retrieval simulations for channel selection, which are discussed in Buehler et al. (2007) and Jiménez et al. (2007). Radiometric noise is not very critical for CloudIce, since the cloud signal is strong. (This is in contrast to missions focused on measuring humidity, such as the Advanced Microwave Sounding Unit (AMSU), where the signal variation due to humidity fluctuations is ten times weaker.)

Compared to earlier mission concepts, we do not include a very high frequency channel at $874 \mathrm{GHz}$. Such a channel would have a benefit, but it is expected to not be very large if $664 \mathrm{GHz}$ is also present, as discussed in Jiménez et al. (2007, Fig. 14, the $874 \mathrm{GHz}$ channel is called "R6" there). Not including $874 \mathrm{GHz}$ is a matter of technical trade-off, since it is technically significantly more expensive and risky than $664 \mathrm{GHz}$. The channel was still present in the CIWSIR ESA mission proposal in 2005, but not in Buehler et al. (2007).

\subsection{Other requirements}

Other important requirements for CloudIce are summarized in Table 4. Below, we briefly comment on the most important requirements.

The viewing geometry of CloudIce is such that the instrument performs a conical scan (the viewing direction rotates around nadir with a fixed earth incidence angle). This requirement has two main reasons. The first reason is 
Table 4. A summary of CloudIce system requirements. Goal, breakthrough, and threshold are given where relevant, otherwise only breakthrough.

\begin{tabular}{|c|c|c|c|c|}
\hline Parameter & Goal & Breakthrough & Threshold & Comments \\
\hline $\begin{array}{l}\text { Viewing geometry } \\
\text { Line of sight scan angle } \\
\text { in azimuth on ward }\end{array}$ & \multicolumn{3}{|c|}{$\begin{array}{l}\text { Conical scan with } 53.5^{\circ} \text { ground incide } \\
\pm 65^{\circ} \text { in satellite } \\
\text { reference frame }\end{array}$} & $\sim 45^{\circ}$ on board elevation angle \\
\hline $\begin{array}{l}\text { Line of sight scan angle } \\
\text { in azimuth back ward }\end{array}$ & $\pm 65^{\circ}$ & $\pm 15^{\circ}$ & $0^{\circ}$ & \\
\hline Crosstrack pixels size & $10 \mathrm{~km}$ & $15 \mathrm{~km}$ & $20 \mathrm{~km}$ & \\
\hline Crosstrack pixels overlap & & $10 \%$ & & \\
\hline On track pixels size & $10 \mathrm{~km}$ & $15 \mathrm{~km}$ & $20 \mathrm{~km}$ & \\
\hline Ontrack pixel overlap & & $10 \%$ & & \\
\hline Collocation of pixels & & Yes, $\pm 10 \%$ pixel size & No & \\
\hline Antenna efficiency & & $>95 \%$ & & \\
\hline Science data dynamics & & 16 bits & & \\
\hline Geolocation & $10 \%$ pixel size & & $30 \%$ pixel size & \\
\hline Operations & & Systematic acquisition & & \\
\hline Latency & $4 \mathrm{~h}$ & & 1 week & $\begin{array}{l}4 \text { hours corresponds to } \\
\text { GPM need }\end{array}$ \\
\hline Orbit & & MetOp orbit & & $\begin{array}{l}800 \mathrm{~km} \text { mean altitude, } \\
\text { 09:30 equat. cross. time }\end{array}$ \\
\hline $\begin{array}{l}\text { Coregistration with } \\
\text { MetOp } \\
\text { (HIRS/AVHRR/IASI) }\end{array}$ & $1 \mathrm{~min}$ & $5 \min$ & $10 \mathrm{~min}$ & \\
\hline Lifetime & $7 \mathrm{yr}$ & $3 \mathrm{yr}$ & $1 \mathrm{yr}$ & \\
\hline
\end{tabular}

that polarization is not consistent or very meaningful for a cross-track scan. The cloud polarization signal itself depends strongly on viewing angle (it is practically zero when looking nadir). Furthermore, in the typical technical implementation of a cross-track scanning instrument, the instrumental polarization characteristics will be scan dependent. This is for example the case for AMSU (Atkinson, 2001).

The second reason for the conical scan requirement is the three-dimensional structure of clouds, view angle biases for cloudy radiances are more difficult to correct than for clearsky radiances. The conical scan ensures that all pixels are viewed with the same incidence angle, largely eliminating view angle biases. (There could be azimuthal view angle biases if weather features have a preferred horizontal orientation, which could be the case for example for fronts. This effect has so far not been studied to the best of our knowledge, but at least biases in azimuth angle can be expected to be much smaller than the known biases in incidence angle.)

The exact incidence angle is not very critical, $53.5^{\circ}$ was chosen as a good compromise between maximum sounding altitude range and maximum horizontal swath range. See Jarret et al. (2007) for a more detailed discussion.

Another viewing geometry parameter is the azimuth scan angle, which describes the part of the conical scan during which actual data collection happens. The azimuth scan angle requirement of $\pm 65^{\circ}$ ensures a broad swath in the forward direction. Side views are scientifically less useful and are therefore used for the radiometric calibration. Optionally, one wants to have also an aft view, even if this is limited to a central part of the scan $\left( \pm 15^{\circ}\right)$. This would allow innovative experimental retrievals, exploiting either the stereo effect due to the nearly opposite azimuth angle, or the short time difference (a few minutes) to study the temporal evolution of convective systems.

Arguably the most important viewing geometry parameter is the spatial resolution. We are assuming spatially continuous sampling, so the spatial resolution is given by the footprint size (also called pixel size). A pixel size of of 10$15 \mathrm{~km}$ is consistent with the resolution of mesoscale circulation models and thus a good scale to study clouds. However, even higher resolution would also give a clear science benefit, since clouds are a multi-scale phenomenon. The spatial resolution of the measurement drives the antenna size, and hence the overall mission mass and cost. The resolution proposed for CloudIce is therefore a compromise between the pure scientific requirements and the increasing cost with increased resolution. See Buehler et al. (2007) for a more detailed discussion.

The next parameter to discuss here is the satellite orbit. The scientific requirement of near global coverage within 
Table 5. Data product definitions.

\begin{tabular}{|c|c|}
\hline Name & Description \\
\hline Tb: & Radiances in units of Planck brightness temperatures. \\
\hline IWP: & $\begin{array}{l}\text { Ice water path in } \mathrm{g} \mathrm{m}^{-2} \text {, the total column value of the mass of ice particles in the } \\
\text { atmosphere. }\end{array}$ \\
\hline Dme: & $\begin{array}{l}\text { Median mass equivalent sphere diameter in } \mu \mathrm{m} \text {. A measure for the characteristic } \\
\text { size of the particle population. }\end{array}$ \\
\hline Zme: & $\begin{array}{l}\text { Median mass cloud altitude in } \mathrm{m} \text {. The altitude where the partial IWP above and } \\
\text { below are equal. A measure for cloud altitude, related to the ice mass (in contrast } \\
\text { to the cloud top altitude). }\end{array}$ \\
\hline CIWC: & $\begin{array}{l}\text { Cloud ice water content in } \mathrm{g} \mathrm{m}^{-3} \text {. The mass of ice (per cubic meter) that is } \\
\text { identified as cloud particles. Model dependent. }\end{array}$ \\
\hline CLWC: & $\begin{array}{l}\text { Cloud liquid water content in } \mathrm{g} \mathrm{m}^{-3} \text {. The mass of liquid water (per cubic meter) } \\
\text { that is identified as cloud droplets. Model dependent. }\end{array}$ \\
\hline GWC: & $\begin{array}{l}\text { Graupel water content in } \mathrm{g} \mathrm{m}^{-3} \text {. The mass of ice (per cubic meter) that is identified } \\
\text { as graupel. Model dependent. }\end{array}$ \\
\hline SWC: & $\begin{array}{l}\text { Snow water content in } \mathrm{g} \mathrm{m}^{-3} \text {. The mass of ice (per cubic meter) that is identified } \\
\text { as snow. Model dependent. }\end{array}$ \\
\hline RWC: & $\begin{array}{l}\text { Rain water content in } \mathrm{g} \mathrm{m}^{-3} \text {. The mass of liquid water (per cubic meter) that is } \\
\text { identified as rain. Model dependent. }\end{array}$ \\
\hline RH: & Relative humidity in percent. \\
\hline TWV: & Total water vapor in $\mathrm{g} \mathrm{m}^{-2}$. The total column mass of water vapor. \\
\hline PR: & $\begin{array}{l}\text { Precipitation rate in } \mathrm{mm} \mathrm{h}^{-1} \text {. The rate of precipitation (liquid and frozen) at the } \\
\text { ground. }\end{array}$ \\
\hline
\end{tabular}

$24 \mathrm{~h}$, together with the requirement of constant local time (to avoid aliasing due to the diurnal cycle), imply a sunsynchronous orbit near $800 \mathrm{~km}$ orbit altitude. However, there is another crucial issue here, namely the requirement for simultaneous infrared data. Retrieval simulations in Jiménez et al. (2007) showed that simultaneous infrared data can significantly improve retrieval performance for clouds with small ice particles and low IWP.

This requirement was in the proposal addressed by flying in formation with MetOp, which fixes all orbit parameters (altitude and local time of ascending node). The time difference requirement of 1-10 min to MetOp comes from the need to observe the same atmospheric state, together with the typical time scale of cloud evolution. Instead of MetOp, other operational meteorological satellites with a standard suite of infrared instruments are also suitable as tandem partners.

Consistent with MetOp, it would be desirable for CloudIce to deliver data in near realtime $(<4 \mathrm{~h}$ latency) to satisfy the needs of numerical weather forecasting. However, for the EE8 proposal this was not a strict requirement, since the mission was primarily intended as a science mission.

We conclude this section with a remark on the mission lifetime, namely, that the technical requirement here follows directly from the scientific lifetime requirement (compare Table 2).

\section{Data analysis}

\subsection{Geophysical variables and data products}

Figure 5 gives an overview of data levels and dependencies, Table 5 gives brief data product definitions. Submillimeter radiances contain information on the cloud ice water content, the ice particle size, their vertical distribution, and, with polarized measurements, their aspect ratio and orientation. As with any remote measurement, the information is indirect, and the retrieval underconstrained to different degrees, depending on product. To account for this, we define a hierarchy of retrieval products, ordered by the amount of a priori information that is needed for the retrieval. Table 6 gives an overview of the different classes of data products. Note, that the concept of retrieval product classes is different from the concept of data levels: L3 data are normally derived from L2 data, but class 3 products are not derived from class 2 products. Table 6 lists also the associated data levels for each product class.

Class 1 products are simply calibrated radiances (data level L1b), in units of Planck brightness temperatures. They require no a priori information. These data are valuable for the interpretation of the radiometric signal relative to the sampled atmosphere (in the presence of cloud and precipitation), for assimilation into circulation models, and for 
Table 6. Retrieval product classes. Classes 1 and 2 are the primary ones, for which the mission is sized. Classes 3 and 4 would be provided on a best-effort basis.

\begin{tabular}{lll}
\hline Name, Description & Data Level & Products \\
\hline $\begin{array}{l}\text { Class 1 } \\
\text { No a priori } \\
\text { "Radiances" }\end{array}$ & L1b & Calibrated radiances \\
$\begin{array}{l}\text { Class 2 } \\
\text { Weak a priori } \\
\text { "Physics based" }\end{array}$ & L2, L3 & IWP, Dme, Zme \\
$\begin{array}{l}\text { Class 3 } \\
\text { More a priori (particularly correlations } \\
\text { between retrieved species) } \\
\text { "Model based" }\end{array}$ & L2', L3' & TWV, PR, profiles of CIWC, CLWC, \\
$\begin{array}{l}\text { Class 4 } \\
\text { Explicit a priori from model forecast } \\
\text { "Assimilation" }\end{array}$ & L3" & SWC, SWC, RWC, and RH \\
\hline
\end{tabular}

\begin{tabular}{|c|c|c|}
\hline \multicolumn{3}{|c|}{ L0 } \\
\hline \multicolumn{3}{|c|}{ L1a } \\
\hline \multicolumn{3}{|c|}{ L1b } \\
\hline L2 & L2' $^{\prime}$ \\
\hline L3 & L3' \\
\hline
\end{tabular}

Fig. 5. Data levels. L0 are raw data. L1a are raw data with calibration coefficients, L1b are calibrated radiances in units of Planck brightness temperatures. L2 and L2' are retrieved parameters for each instrument field of view. L3, L3', and L3" are retrieved parameters on standard grids. The processing chain progresses from the top down, so $\mathrm{L} 3^{\prime}$ depends on $\mathrm{L} 2^{\prime}$, and so on. $\mathrm{L} 3^{\prime \prime}$ is special, because it depends directly on L1b.

cloud/radiative transfer model evaluation. Recent examples for the direct use of radiances for scientific studies are Nesbitt and Zipser (2003) and Prigent et al. (2005). The CloudIce science team provides a forward operator (a radiative transfer model), which is essential for the use of these data.

Calibrated radiances would also be useful as input to advanced multi-sensor retrieval algorithms that combine collocated data from different instruments and missions. A good example for such an approach is the combined radar, lidar, and infrared radiometer data product DARDAR by Delanoë and Hogan (2008). The most obvious complementary data to CloudIce would be infrared radiances, both due to their availability, and because retrieval simulations (e.g. Jiménez et al., 2007) show that they improve the IWP retrieval from submillimeter radiances.

The next retrieval product class is class 2 . These are the relatively simple parameters IWP, Dme, and Zme (see Table 5 for definitions and units). The data level of these products is L2 (for instrument fields of view) and L3 (gridded).
These products are still "close" to the measurement in the sense that they require only weak a priori information, in the form of assumptions on the statistics of cloud vertical structure and microphysics. Products are obtained by a retrieval scheme, based on standard mapping and regression techniques, such as neural networks or Bayesian Monte Carlo integration. Class 2 products are the core parameters of the CloudIce mission.

It should be noted that for clear-sky scenes the mission would also provide high quality upper tropospheric humidity (UTH) data, with the same retrieval approach as described, for example, in Buehler et al. (2008) and Buehler and John (2005). But for the EE8 proposal it was decided to not use that capability for mission sizing.

The next retrieval product class, class 3, provides a richer set of hydrological parameters, namely profiles of five different hydrometeor types: Cloud ice water content (CIWC), cloud liquid water content (CLWC), graupel (GWC), snow (SWC), rain (RWC), and relative humidity (RH). Additionally, class 3 provides total column water vapor (TWV) and the precipitation rate at the surface (PR). See Table 5 for definitions and units of the different parameters. As for class 2, these products are derived from the L1b data, so we call the data levels for class $3 \mathrm{~L} 2$ ', and for gridded data L3'.

Whereas class 2 data are relatively "close" to the measurement, class 3 data are "close" to atmospheric models. A mesoscale circulation model is used to generate the training data, and the retrieved parameters are those that represent humidity, clouds, and precipitation in the model. The training data thus contain implicit information on the correlation of the different hydrometeor species according to the model. This allows the retrieval of parameters that are measured indirectly, such as the precipitation rate. This works well, since the physical mechanism for generating many types of precipitation is through the ice phase, and hence the precipitation rate is strongly correlated with the amount of cloud ice. 
Table 7. Example use cases for CloudIce data.

\begin{tabular}{|c|c|c|}
\hline Topic & Where & Data \\
\hline $\begin{array}{l}\text { Convection Scheme Development } \\
\text { Needs statistics of occurrence, extent, and IWP of convective } \\
\text { clouds. }\end{array}$ & Met. Agency & $\begin{array}{l}\text { IWP (L2), hydrometeor } \\
\text { profiles }\left(\mathrm{L2}^{\prime}\right)\end{array}$ \\
\hline $\begin{array}{l}\text { Microphysics Scheme Development } \\
\text { Scheme uses a mix of physical approximations and statistical } \\
\text { assumptions. Needs statistics on Dme and IWP. }\end{array}$ & $\begin{array}{l}\text { Met. Agency/ } \\
\text { University/ } \\
\text { Research Institute }\end{array}$ & IWP, Dme (L2, L3) \\
\hline $\begin{array}{l}\text { Climate Model Evaluation } \\
\text { Evaluate climate model with new cloud physics, requires global } \\
\text { data for several years. Compare model and data mean state } \\
\text { and variability in IWP. Can alternatively be done in radiance } \\
\text { space, using forward operator. }\end{array}$ & $\begin{array}{l}\text { Climate modeling } \\
\text { center }\end{array}$ & $\begin{array}{l}\text { Entire L3 dataset (or entire } \\
\text { L1B dataset) }\end{array}$ \\
\hline $\begin{array}{l}\text { Case Studies on Frontal Precipitation } \\
\text { Compare CloudIce data to mesoscale model simulations. }\end{array}$ & $\begin{array}{l}\text { University/ } \\
\text { Research Institute }\end{array}$ & Hydrometeor profiles ( $\left.\mathrm{L}^{\prime}{ }^{\prime}\right)$ \\
\hline $\begin{array}{l}\text { Role of Convective Ice Clouds in Moistening the UT } \\
\text { Correlate cloud ice and humidity data to assess the relevance } \\
\text { of cloud ice particles in moistening the upper troposphere. }\end{array}$ & $\begin{array}{l}\text { University/ } \\
\text { Research Institute }\end{array}$ & $\begin{array}{l}\text { Hydrometeor profiles }\left(\mathrm{L}^{\prime}\right) \\
\text { plus humidity }\left(\mathrm{L}^{\prime}\right)\end{array}$ \\
\hline $\begin{array}{l}\text { Precipitation Statistics } \\
\text { Calculate regional statistics of precipitation over land in areas } \\
\text { without weather radar network. }\end{array}$ & $\begin{array}{l}\text { University/ } \\
\text { Research Institute }\end{array}$ & Precipitation rate $\left(\mathrm{L}^{\prime}\right)$ \\
\hline $\begin{array}{l}\text { Weather Forecasting } \\
\text { Use IWP maps as a support tool to interpret the model } \\
\text { analysis/forecast. }\end{array}$ & Met. Agency & L2 (realtime) \\
\hline $\begin{array}{l}\text { Operational } N W P \\
\text { Assimilate CloudIce radiances. }\end{array}$ & Met. Agency & Radiances (L1b, realtime) \\
\hline $\begin{array}{l}\text { Radiative Transfer Scheme Development } \\
\text { Develop fast scheme for radiation flux, taking into account } \\
\text { particle asphericity. Needs CloudIce data for assumptions on } \\
\text { size and asphericity. }\end{array}$ & $\begin{array}{l}\text { University/ } \\
\text { Research Institute }\end{array}$ & L2, L1b (polarized) \\
\hline $\begin{array}{l}\text { Volcano Ash Mass Ejection Estimate } \\
\text { Estimate ash particle single scattering properties from } \\
\text { assumed refractive index. Retrieve ash total column in intense } \\
\text { plume near the source. Estimate total mass by assuming } \\
\text { continuity between daily observations. }\end{array}$ & $\begin{array}{l}\text { University/ } \\
\text { Research Institute }\end{array}$ & Radiances (L1b) \\
\hline
\end{tabular}

The retrieval algorithm itself is similar to class 2 (a neural network).

In contrast to class 2 , class 3 data depend on the cloud model that is used for training the algorithm. They are thus not the best suited data class to evaluate other models (there class 1 is best). But class 3 provides a complete picture of the hydrological state and would be very useful for case studies.

The last product class, class 4, results from assimilating $\mathrm{L} 1 \mathrm{~b}$ radiances into an atmospheric circulation model. We assign data level L $3^{\prime \prime}$ to this product class. There is no data level $\mathrm{L} 2^{\prime \prime}$, since L $3^{\prime \prime}$ is generated directly from L1b. For class 4 , a mesoscale circulation model is used not only for training data generation, as for class 3 , but explicitly in the assimilation process. The a priori information for the derived products is the model forecast. The variables considered are the same as for class 3 . Class 4 would give the best estimate of the true state, but would be furthest from the "pure" measurements. Assimilation of cloudy radiances into circulation models is still experimental. We expect significant progress in this area in the coming years. For the moment this class is speculative.

Table 7 lists some examples how CloudIce data might be used in practice. These are intended as illustrative examples, not as an exhaustive list.

\subsection{Retrieval algorithms}

In this section we briefly describe the retrieval approach for the different product classes and note their algorithm development status. 


\subsubsection{Class 1 "radiances"}

Instrument counts have to be properly calibrated to radiances in units of Planck brightness temperature, using the coldspace and internal hot load calibration measurements that are performed in each scan cycle (L0 to L1b processing). The procedure would be similar to the one for existing operational instruments of the AMSU-B/MHS family, as described for example in Lambrigtsen (2003). Data quality control would also be an important activity for this class. Beyond that, class 1 does not require a retrieval algorithm, but it requires that data users be provided with a forward operator in the form of a fast radiative transfer (RT) computer program. The program should allow modelers an easy adaptation to the cloud microphysical assumptions of their specific model. This also requires an accurate reference RT program, for development and validation of the fast program.

The L0 to L1b data processing and quality control are straightforward, using established procedures. Concerning the forward operator, the public domain RT code ARTS (Eriksson et al., 2011a; Buehler et al., 2005) is available as reference RT code for CloudIce. It was developed to handle all aspects of submillimeter cloud ice observations. The development was partially funded by ESA in a study reported by Sreerekha et al. (2006). ARTS simulates the full Stokes vector, so it is applicable for polarized measurements. Also, it includes two different algorithms to simulate scattering by cloud particles (Emde et al., 2004; Davis et al., 2005).

The latter algorithm allows full three-dimensional (3-D) simulations. In Davis et al. (2007), it was shown that true 3-D effects from the RT itself are small for this viewing geometry, but that "beam-filling" effects due to scene inhomogeneity are significant. The 3-D model setup has the advantage that those effects can be treated more easily than in a 1-D model.

Scattering RT simulations require single scattering data. Different options are available here, used so far by the CloudIce community was either the T-matrix method (Mishchenko and Travis, 1998), or the single scattering database by Hong et al. (2009), which was computed with the discrete dipole approximation.

Further to the scattering algorithm development, recent other developments (Buehler et al., 2011, 2010) allow that ARTS is also used for RT simulations in the infrared, which is important for joint retrievals from submillimeter and collocated IR data.

There is not yet a fast RT model for CloudIce. The best option would be to implement this as part of the RTTOV (Saunders et al., 1999) model, which provides fast forward operators for all operational meteorological missions. Since the current version of RTTOV already includes scattering, the implementation of the CloudIce channels is expected to be fairly straightforward, since the reference model is readily available. It was already shown in Buehler et al. (2006) that for the clear-sky case ARTS and RTTOV are in good agreement.

\subsubsection{Class 2 "physics based"}

The retrieval approach for class 2 products consists of two distinct steps. Firstly, creating an atmospheric profile database with realistic statistics of temperature, water vapor, cloud profiles, and cloud microphysics (size, shape, and orientation distributions), based on in-situ and remote measurements. Secondly, using this database to approximate the a posteriori distribution of the atmospheric state, given the observation. The retrieved state is then selected from the a posteriori distribution by some appropriate criterion (e.g. the mean value). Different standard methods to numerically estimate the retrieved state are readily available, notably Bayesian Monte Carlo integration and neural networks. The former is conceptually simpler and automatically provides an estimate of the retrieval error. The latter is computationally more efficient, but the derivation of retrieval errors is less straightforward. These two methods are described well in Rydberg et al. (2009).

Extensive retrieval simulations with different submillimeter channel combinations and different training databases have been carried out in the ESA study reported by Jarret et al. (2007). These results have also been published in Jiménez et al. (2007), which deals with the retrieval simulations themselves, and in Buehler et al. (2007), which deals with the overall instrument and mission concept.

\subsubsection{Class 3 "model based"}

The approach for class 3 data is similar to class 2, but the source of the training data is a mesoscale circulation model, instead of measured data. The retrieved parameters are the different microphysics species and state parameters of the model. The approach is therefore model dependent, but the validity of the model can be checked by comparing its outputs to concurrent ground-based and space-based observations. Retrieval simulations for class 3 products have been carried out and are described in Sect. 4.3.

\subsubsection{Class 4 "assimilated"}

The approach for class 4 data is direct assimilation of the CloudIce L1b radiances into a mesoscale circulation model. Already today, weather centers such as ECMWF operationally assimilate cloud and precipitation-affected radiances from microwave imagers (Bauer et al., 2006a,b). There has been rapid development in this area in recent years, and it is reasonable to assume that in the foreseeable future also high frequency imager data can be treated in the same way.

\subsection{Retrieval demonstrations}

\subsubsection{Class 2 products retrieval simulation study}

Detailed retrieval simulations of the class 2 products IWP, Dme, and Zme were carried out in a recent ESA study (Jarret 
et al., 2007). Different channel combinations were investigated, in order to determine an optimum instrument configuration. The retrieval algorithm was as outlined in Sect. 4.2. The setup is described in detail in Jiménez et al. (2007).

As explained in Sect. 4.2, the retrieval algorithm needs training data, consisting of simulated radiances for a diverse atmospheric state dataset. Two different diverse datasets have been developed. D1, developed by Evans et al. (2005), uses randomly generated profiles and microphysics. Statistics for the vertical structure are taken from radiosondes and statistics for the microphysics are taken from aircraft campaigns. D2, developed by Rydberg et al. (2007), uses cloud radar data for the vertical structure, and combines them with randomly generated microphysics. As for D1, microphysics statistics are taken from aircraft campaigns.

The retrieval simulations in Jiménez et al. (2007) used both datasets, D1 and D2, but in both cases versions that were generated specifically for that study, so dataset versions are not identical to the versions used in the two papers that are cited in the previous paragraph. But the method of generating the data is in both cases as described in the articles.

Having different databases available is crucial to test the dependence of the retrieved products on the a priori assumptions. Results in Jiménez et al. (2007), where inversions using D1 and D2 were compared, showed consistency between both derived IWPs.

Figure 11 in Buehler et al. (2007) shows the expected retrieval performance for IWP, Dme, and Zme based on dataset D1. These simulations confirm that the mission can meet its scientific requirements.

\subsubsection{Class 3 products retrieval simulation study}

Radiative transfer simulations have been performed with the help of an RT model based on realistic atmospheric/microphysics profiles derived from the MESO-NH cloud-resolving model in an ESA study (Zanifé et al., 2007). The RT simulations are in good agreement with coincident AMSU and SSM/I observations (Chaboureau et al., 2008; Meirold-Mautner, 2007). The neural network retrieval scheme is built from a synthetic database composed of realistic atmospheric/microphysics profiles derived from the cloud-resolving model and concurrent simulated brightness temperatures for sea and land separately (Defer et al., 2008), and for different atmospheres (Charlton et al., 2010).

The database was used to explore the information contents that can be derived from submillimeter observations (Zanifé et al., 2007; Mech, 2007) and to confirm the pertinence of submillimeter radiometry in quantifying precipitation (Zanifé et al., 2007; Defer et al., 2008). The same method was recently applied in an ESA study to assess the performance of an airborne demonstrator at mid-latitude and tropical atmospheres (Charlton et al., 2010).

Figure 6 demonstrates the capability of CloudIce to retrieve hydrometeor vertical profiles. The hydrometeor species retrieved are the five species of MESO-NH: cloud ice, graupel, snow, rain, and cloud liquid. (In Tables 5 and 6 these products are labeled CIWC, GWC, SWC, RWC, and CLWC, respectively.) The microphysical properties of the different species are summarized in Table 3 of Chaboureau et al. (2008).

Preliminary retrieval schemes, over sea and land separately, were applied to derive hydrometeor profiles from simulated noisy brightness temperatures. The retrieved hydrometeor profiles are then compared to the original profiles. As shown in the figure, cloud regions with significant ice content are well-captured and similar vertical cloud structures can be found in the retrieved transect relative to the original one.

One of the mission objectives of CloudIce is to validate the capability of submillimeter radiometry for precipitation retrieval. Radiometry at these wavelengths is predominantly sensitive to cloud ice particles, and precipitation detection and quantification mainly relies on the correlation of precipitation with the ice particles above. The retrieval error for the precipitation rate was evaluated, using the microphysics/brightness temperature database. Table 8 shows that the CloudIce radiometer should be able to detect precipitation events with a detection threshold of $2-3 \mathrm{mmh}^{-1}$, and could provide precipitation rate above $10 \mathrm{~mm} \mathrm{~h}^{-1}$ with an error range of 30-60\%. Comparing this to the recent EUMETSAT Position Paper (Rizzi et al., 2006) reveals that the performance is near the breakthrough level for global and regional NWP applications, but poorer than the threshold level for hydrology applications.

\subsubsection{Aircraft data}

Aircraft instruments play a key role for retrieval algorithm validation and fine-tuning. Furthermore, they allow exciting scientific studies in their own right. For both applications it is crucial that these instruments are deployed within coordinated campaigns, so that complementary data from other sensors are available. The CloudIce scientific community will soon be able to use three such instruments, as summarized in Table 9. We will here focus on the results from only one of these instruments, CoSSIR.

The Compact Scanning Submillimeter-wave Imaging Radiometer (CoSSIR, Column 2 in Table 9) was built at the NASA Goddard Spaceflight Center. During the Tropical Composition, Cloud, and Climate Coupling (TC4) field campaign (Toon et al., 2010) in July and August 2007, CoSSIR flew on the NASA ER-2. For that deployment CoSSIR had 11 channels with receivers at $183,220,380,640$, and $874 \mathrm{GHz}$, and dual polarization at $640 \mathrm{GHz}$, all with $4^{\circ}$ beam widths. CoSSIR performed forward and aft conical scans at $53^{\circ}$ plus two quick scans through nadir in each 10 second scan cycle.

Figure 7a shows the forward conical scan brightness temperatures from part of one flight during TC4. The higher frequencies $(640$ and $874 \mathrm{GHz}$ ) are seen to be more sensitive than the lower frequencies (183 and $220 \mathrm{GHz}$ ) to the smaller 

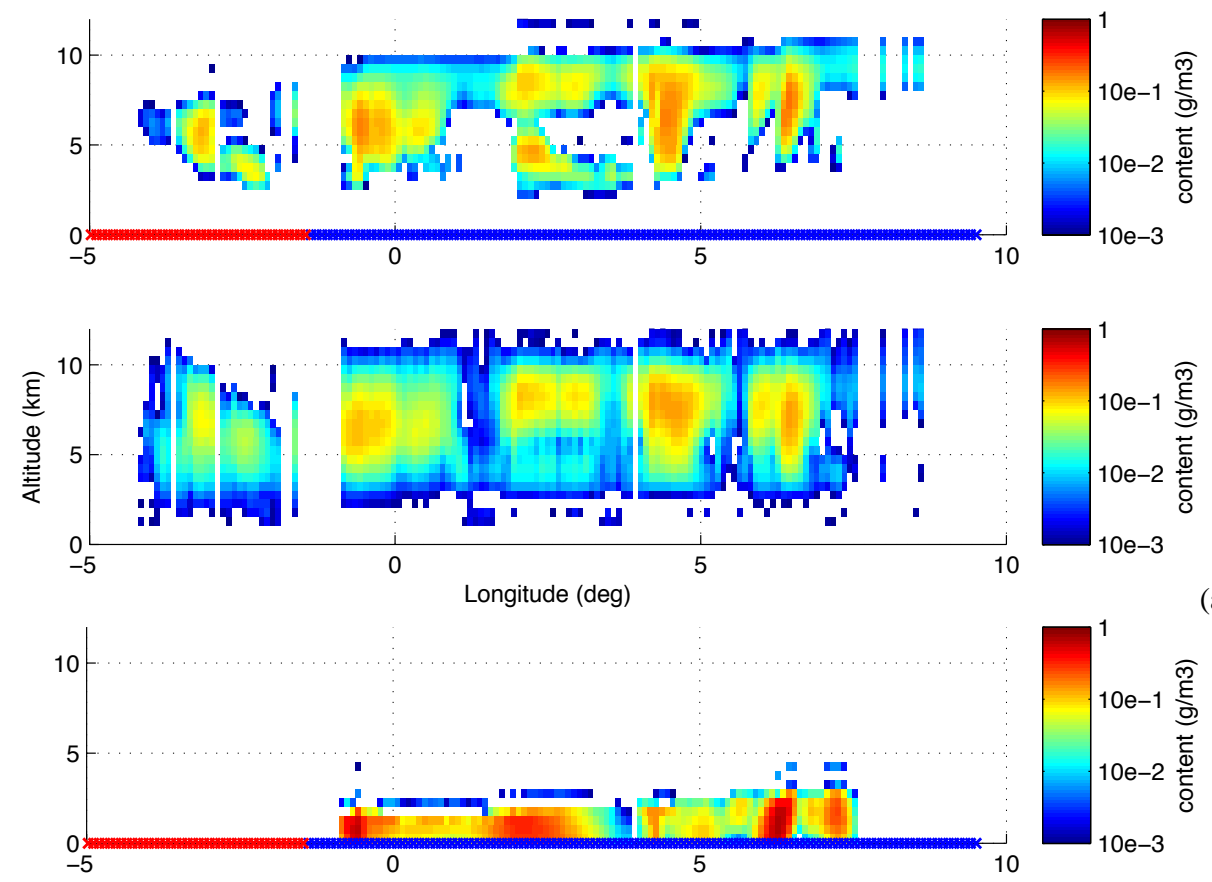

(a)
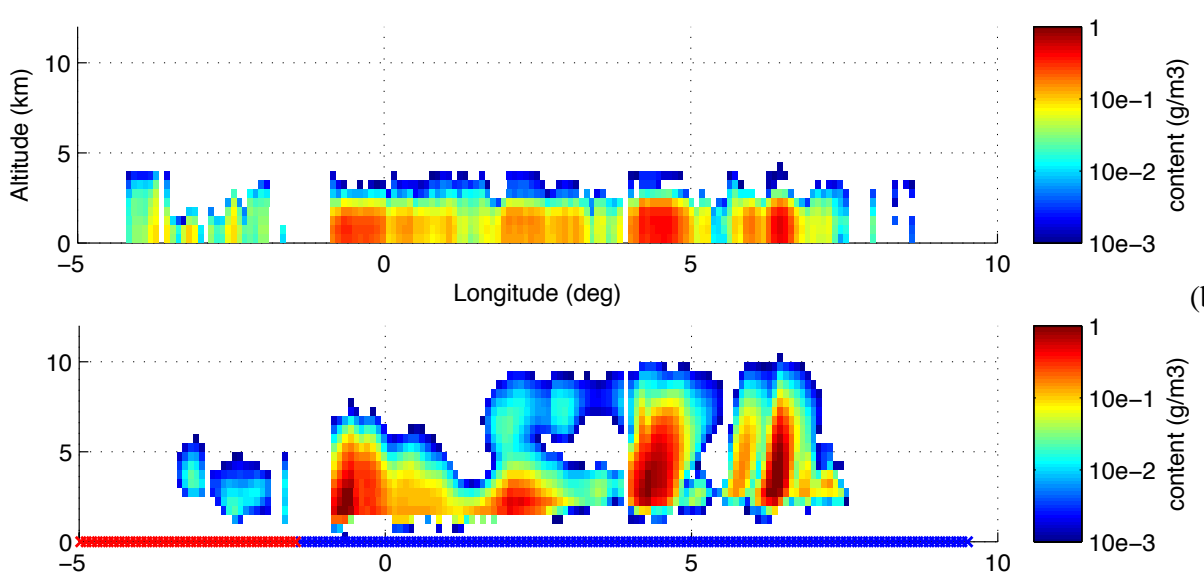

(b)

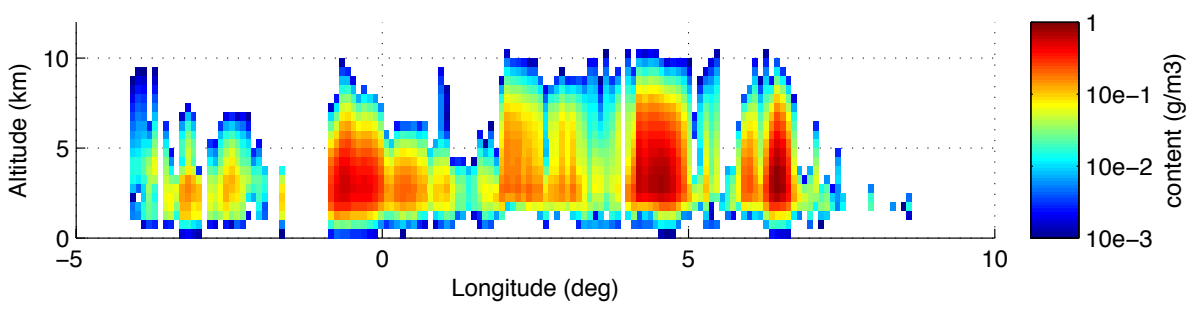

(c)

Fig. 6. Caption on next page.

ice particles in the anvil (e.g. at 16.6 UTC) adjacent to the convective core. The multiple channels around the 183.3 and $380.2 \mathrm{GHz}$ water vapor lines are seen to have vertical profile information with only the highest altitude ice cloud features appearing in the channels with the highest altitude weighting functions. Small differences between the $640 \mathrm{H}$ and $640 \mathrm{~V}$ channels are apparent.
Submillimeter-wave brightness temperature polarization differences are indicative of higher aspect ratio ice particles (such as columns or plates) being horizontally aligned (e.g. Evans and Stephens, 1995). Figure 7b shows a retrieved polarization index, which is defined as the difference between $\mathrm{V}$ and $\mathrm{H}$ polarization, normalized by the cloud signal. In anvil regions, this index has values from 0.15 to 0.25 , 

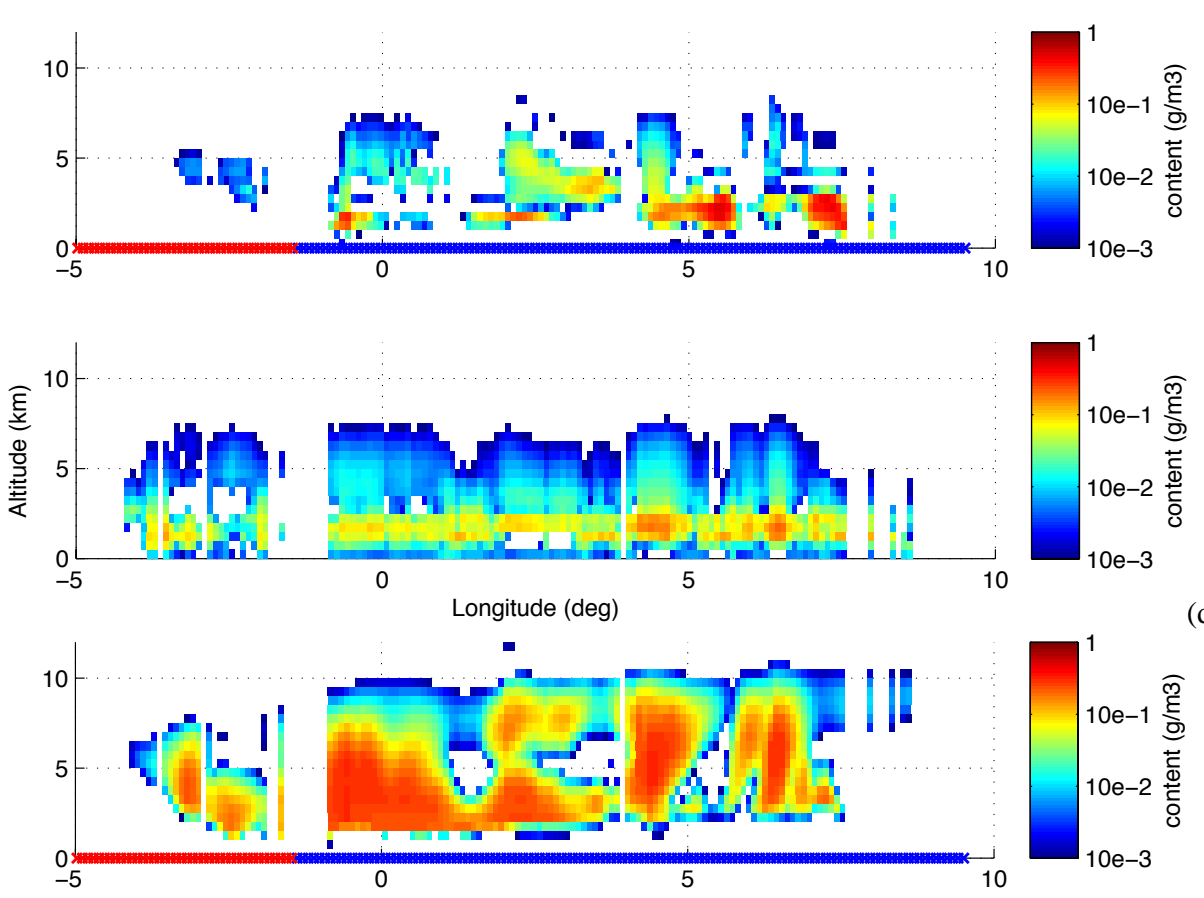

(d)

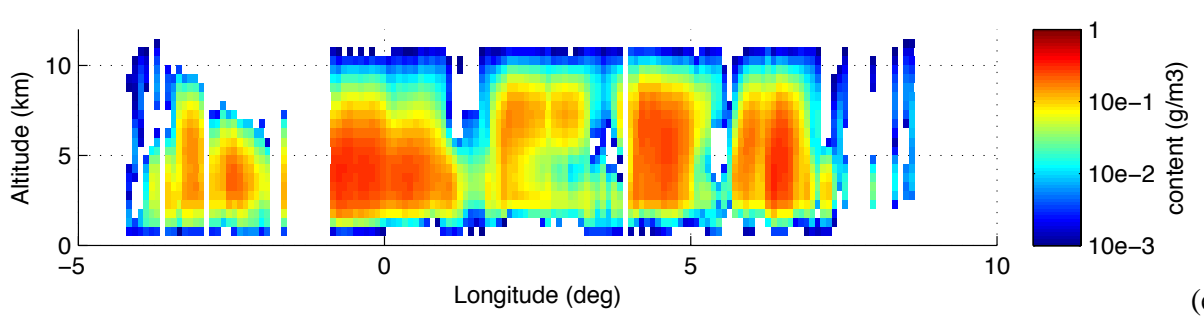

(e)

Fig. 6. Hydrometeor content profile retrieval for the MESO-NH microphysics species cloud ice, graupel, snow, rain, and cloud liquid. For each species, original (top panels) and retrieved (bottom panels) profiles are shown along a longitudinal transect for a simulated case over the Mediterranean Sea (the Algier case of the SIMGEO database, Chaboureau et al., 2008). Sea and land surface cases are indicated in blue and red in each top panel. (a) Ice, (b) rain, (c) graupel, (d) liquid and (e) snow.

Table 8. Estimated RMS error (in \%) of precipitation rate for 3 different ranges. The last three columns show the corresponding threshold accuracies (and breakthrough accuracies in parentheses) for different applications. Applications considered are numerical weather prediction (NWP) and hydrology, with requirements taken from the EUMETSAT Position paper (Rizzi et al., 2006).

\begin{tabular}{llccc}
\hline $\begin{array}{l}\text { Precipitation } \\
\text { rate range }\end{array}$ & $\begin{array}{l}\text { CloudIce RMS } \\
\text { retrieval error }(\%)\end{array}$ & $\begin{array}{c}\text { NWP global } \\
(\%)\end{array}$ & $\begin{array}{c}\text { NWP regional } \\
(\%)\end{array}$ & $\begin{array}{c}\text { Hydrology } \\
(\%)\end{array}$ \\
\hline$<1 \mathrm{~mm} \mathrm{~h}^{-1}$ & Not retrievable & $100(50)$ & $100(50)$ & $80(40)$ \\
$1-10 \mathrm{~mm} \mathrm{~h}^{-1}$ & $50-70$ & $100(50)$ & $100(50)$ & $40(20)$ \\
$>10 \mathrm{~mm} \mathrm{~h}^{-1}$ & $30-60$ & $100(50)$ & $100(50)$ & $20(10)$ \\
\hline
\end{tabular}

indicating oriented ice crystals. The convective core, on the other hand, has low polarization index, presumably indicating quasi-spherical tumbling ice particles, such as graupel.

Retrievals of IWP and Dme were performed with a Bayesian Monte Carlo integration algorithm described in Evans et al. (2005). A priori information is represented by a dataset of profiles of atmospheric and ice cloud properties generated from statistics relating temperature, IWC, and
Dme (from in situ microphysical probes), and statistics of temperature and relative humidity (from TC4 radiosondes). The dataset contains $10^{6}$ cases. One difference of these retrievals from Evans et al. (2005) is that the Bayesian integration is done with $\ln (\mathrm{IWP})$ and $\ln (\mathrm{Dme})$. Figure $7 \mathrm{c}$ and $\mathrm{d}$ shows the retrieved IWP and Dme with the uncertainty range. There was no way to directly validate IWP during TC4, but an indirect validation was made by comparison to the nadir 
a)

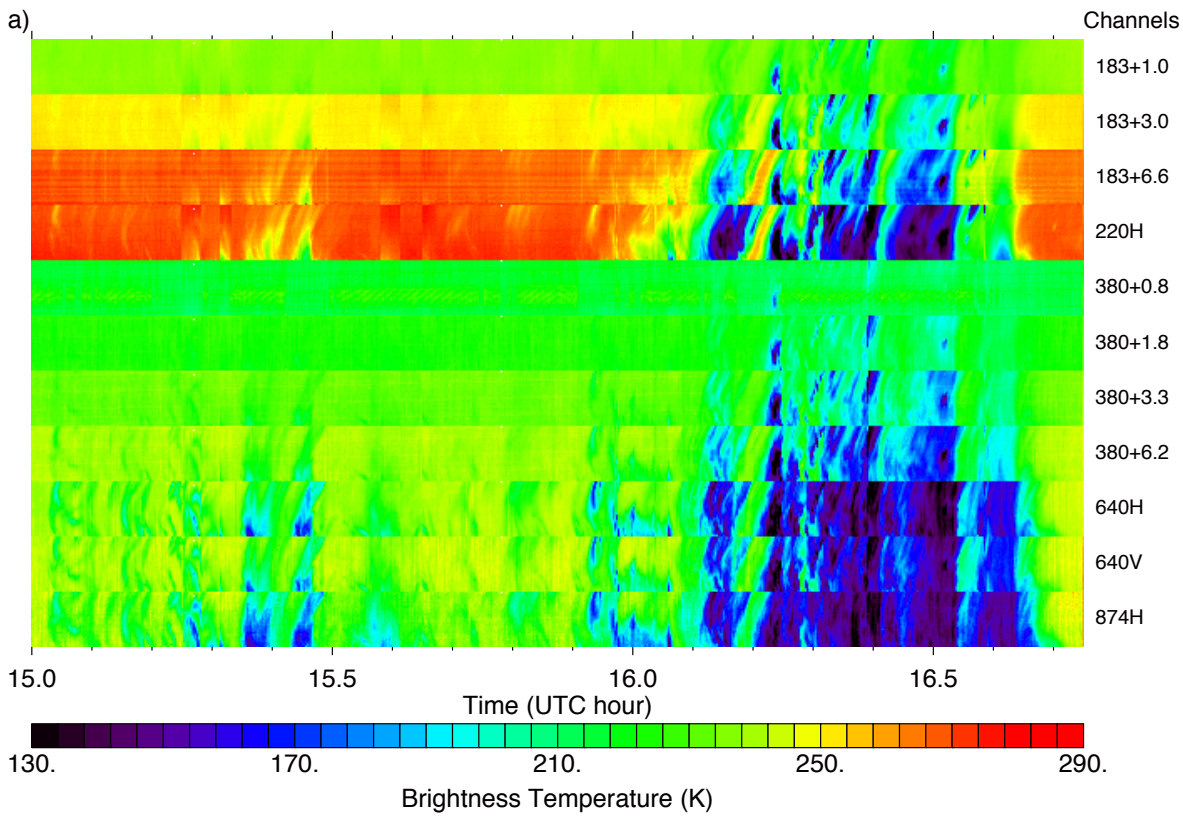

b)
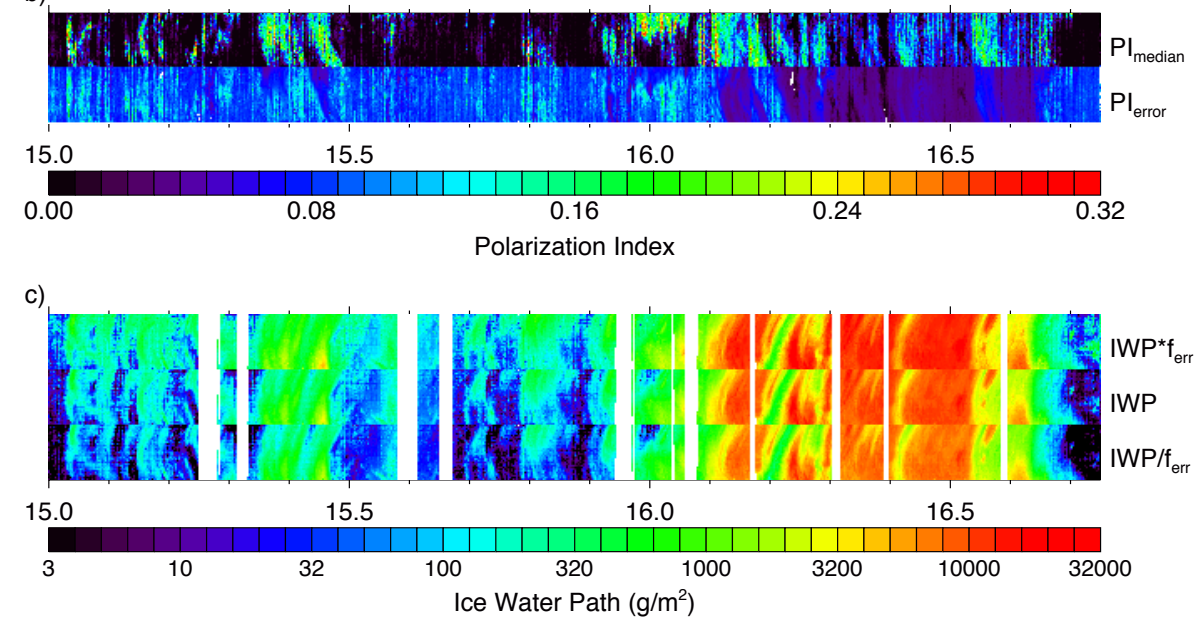

d)

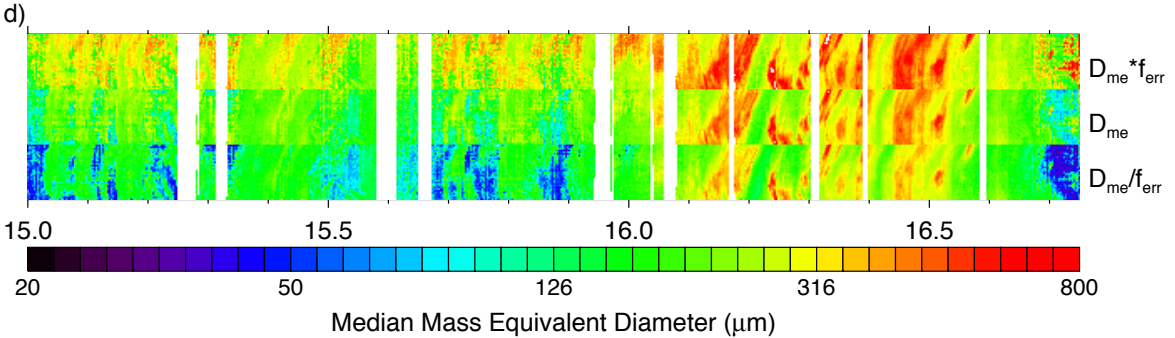

Fig. 7. CoSSIR forward conical scan swath images from 17 July 2007 showing (a) brightness temperatures for the 11 channels, (b) retrieved $640 \mathrm{GHz}$ polarization index (median and RMS error), (c) retrieved ice water path, and (d) retrieved median mass diameter. The retrieved error range for IWP and Dme are shown using the error factor, ferr, which is the exponential of the RMS error of $\ln (\mathrm{IWP})$ or $\ln (\mathrm{Dme})$. Retrievals are not performed during turns of the ER-2 aircraft, leaving the white vertical bars.

viewing $94 \mathrm{GHz}$ Cloud Radar System. CoSSIR nadir viewing brightness temperatures are used to retrieve vertically integrated $94 \mathrm{GHz}$ backscattering, which is compared to the integral of the measured radar reflectivity profile. Figure 8 shows good agreement, usually comparable to the retrieved error bars, in integrated radar backscatter over a large range. This good agreement lends confidence to the submillimeterwave retrievals of IWP and Dme.

CoSSIR has recently been upgraded to more closely match the frequency configuration for the proposed 
Table 9. A summary of airborne submillimeter-wave radiometers of interest to the CloudIce science community. ISMAR is still under development, the other two instruments are already available.

\begin{tabular}{|c|c|c|c|}
\hline Instrument & CoSSIR & PSR-S & ISMAR \\
\hline Agency & NASA & $\begin{array}{l}\text { University of Colorado } \\
\text { at Boulder }\end{array}$ & Met Office (UK)/ESA \\
\hline PI & F. Evans & A. Gasiewski & C. Lee \\
\hline Aircraft & ER-2, WB-57 & $\begin{array}{l}\text { P-3, DC-8, ER-2, } \\
\text { WB-57, Geophysica }\end{array}$ & $\begin{array}{l}\text { FAAM (possibly } \\
\text { HALO) }\end{array}$ \\
\hline Reference & Evans et al. (2005) & $\begin{array}{l}\text { Piepmeier and } \\
\text { Gasiewski (1996) } \\
\text { (note that article is for } \\
\text { a different PSR } \\
\text { scanhead) }\end{array}$ & Charlton et al. (2010) \\
\hline Channels [GHz] & $\begin{array}{l}183.3(3), 325.1(3) \\
448(3), 640(V+H) \\
874\end{array}$ & $\begin{array}{l}183,340,380,424 \\
\text { (several channels per } \\
\text { line) }\end{array}$ & $\begin{array}{l}118.75(5), 243.3 \\
(\mathrm{~V}+\mathrm{H}), 325.25(3), 448 \\
(3), 664(\mathrm{~V}+\mathrm{H}) \\
\text { Also available from } \\
\text { MARSS/Deimos: } \\
23.8(\mathrm{~V}+\mathrm{H}), \\
50.1(\mathrm{~V}+\mathrm{H}), 89(\mathrm{~V}+\mathrm{H}), \\
183.3(3) \\
\text { Additionally planned: } \\
424(3), 874(\mathrm{~V}+\mathrm{H})\end{array}$ \\
\hline
\end{tabular}

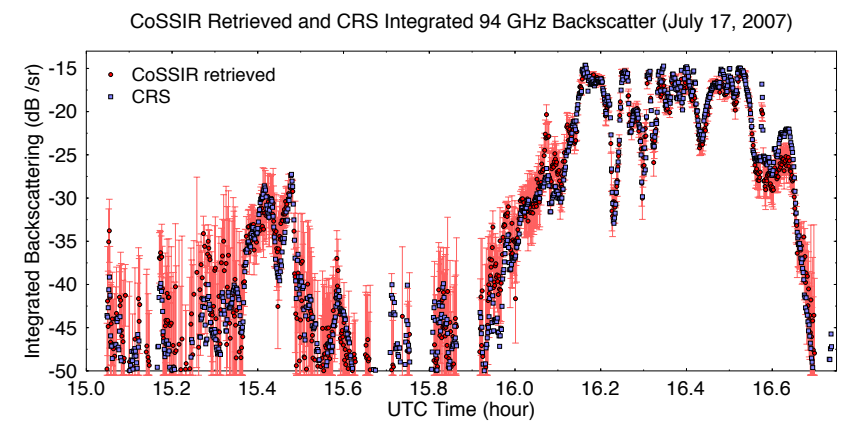

Fig. 8. CoSSIR retrieved nadir viewing vertically integrated $94 \mathrm{GHz}$ backscattering (with error bars) and integrated backscattering from the $94 \mathrm{GHz}$ Cloud Radar System.

submillimeter-wave radiometer on the planned NASA ACE2 mission. This brings it also closer to the CloudIce configuration. There are now three channels each around the 183.3, 325.1 , and $448.0 \mathrm{GHz}$ water vapor absorption lines, dual polarization at $640 \mathrm{GHz}$, and a channel at $874 \mathrm{GHz}$. Test flights of the new CoSSIR configuration over clear skies in August 2009 were successful, with good noise performance for the new 325 and $448 \mathrm{GHz}$ receivers.

A new aircraft instrument, ISMAR (International SubMillimetre Airborne Radiometer), is being developed which includes the key frequencies identified in Charlton et al. (2010) for both cirrus and precipitation measurements. It has been designed to be modular such that channels up to $874 \mathrm{GHz}$ can be added in stages, some of which are funded by Met Office (UK) and ESA. The instrument has been certified to operate on the BAe 146-301 FAAM aircraft, which has a range of auxiliary instrumentation from microwave radiometers (MARSS and Deimos) to infrared and visible spectrometers, as well as in-situ cloud physics measurements. The full range of microwave and submillimetre channels planned are shown in Table 9.

ISMAR will be used as a satellite demonstrator, for scientific applications and ultimately cal/val once a submillimeter satellite is launched. Scientifically, ISMAR will be used in aircraft field campaigns to improve and test radiative transfer algorithms, perform submillimeter radiation and cloud microphysics closure, measure surface emissivity, as well as provide proof of the satellite concepts.

ISMAR has two on-board blackbody targets at different temperatures such that calibrations can be made in flight. Its viewing geometry is $+55^{\circ}$ to $-10^{\circ}$ nadir and $+10^{\circ}$ to $-40^{\circ}$ zenith along-track. It has also been designed to be autonomous, with all the electronics located at the instrument, such that it can be installed relatively easily on to other aircraft platforms, for example HALO.

\subsubsection{Operational millimeter-wave data}

There is no operational down-looking submillimeter satellite instrument, but the AMSU-B/MHS instrument family provides at least measurements around the $183.31 \mathrm{GHz}$ water vapor line, which would also be observed by CloudIce. 
Together with collocated CloudSat data, these data can therefore be used to demonstrate the CloudIce retrieval, although with much poorer performance than CloudIce would have.

Holl et al. (2010) describe this in a recent article. They demonstrate that radiative transfer model, CloudSat radar measurement, and MHS brightness temperature signal are all consistent, within the expected uncertainty. Furthermore, they implement a simple IWP retrieval from the MHS data, assuming that the CloudSat IWP measurement represents the truth. The MHS retrieval performance is found to be consistent with the CloudIce simulations as described in Jiménez et al. (2007), when they are restricted to use only the MHS channels. Another case study with operational microwave data, comparing them to model-based RT simulations, is discussed in Sreerekha et al. (2008).

It should be mentioned that the currently available IWP products from AMSU-B/MHS agree only quite poorly with CloudSat radar data, a fact that has been observed independently by $\mathrm{Wu}$ et al. (2009) and Eliasson et al. (2011). (The former use the IWP retrieval method by Zhao and Weng, 2002, the latter the operational NOAA/NESDIS IWP product, Ferraro et al., 2005, which also builds on Zhao and Weng, 2002.) For thinner clouds the poor agreement is expected, due to the lacking sensitivity of AMSU-B/MHS for these clouds. But for thick clouds (IWP above approximately $100 \mathrm{~g} \mathrm{~m}^{-2}$ ), where the agreement is also poor, the reason is unclear.

\subsubsection{Submillimeter-wave limb sounder data}

No down-looking submillimeter satellite instrument has yet been launched, as mentioned, but several submillimeter limb sounders, notably Odin-SMR and Aura MLS. Both instruments scan down below the point where the transmission through the troposphere approaches zero. This situation is encountered for tangent altitudes below approximately $10 \mathrm{~km}$. For this tangent altitude range the basic properties of the observations are the same as for CloudIce, although the incidence angles are considerably higher. A consequence of the high incidence angle is that only relatively high clouds can be seen by these instruments.

Several cloud ice retrieval studies for limb sounders have been published. For Odin-SMR, the latest retrieval approach for IWC is described in Rydberg et al. (2009), which is based on Evans et al. (2005). In Rydberg et al. (2009), special attention was given to generating the retrieval training database, where CloudSat observations were used to ensure that both vertical and (local) horizontal cloud structures are correctly represented (see Fig. 3 in Rydberg et al., 2009).

For Aura MLS, Wu et al. (2008) presents IWC and (partial) IWP retrievals. In a second article, Wu et al. (2009) compare the MLS cloud ice data to CloudSat and other collocated data, including in-situ observations. The comparison focuses on normalized IWC probability density functions (PDFs). MLS and CloudSat IWC PDFs are found to agree well under conditions where both instruments are inside their sensitivity range, with relative difference below $50 \%$ (with differences increasing with increasing IWC).

In summary, the limb sounder ice cloud data have been analyzed in detail (compared to climate model data and other measurements) and appear to have a high quality. Their usefulness is demonstrated for example in Eriksson et al. (2010), where the diurnal cycle of IWC in the tropical upper troposphere is analyzed by combining CloudSat and SMR retrievals, and where it is shown that climate models still fail to represent this cycle correctly.

\section{Summary and conclusions}

A mission similar to CloudIce can deliver urgently needed global data on ice clouds, particularly on the so far poorly characterized "essential climate variable" ice water path (IWP) and on ice particle size. It can deliver data with near global spatial coverage every $24 \mathrm{~h}$, and on a spatial scale consistent with future global climate models, to both evaluate and improve the models. It can also demonstrate the benefit of submillimeter observations for precipitation retrieval, an important step towards a possible future deployment of submillimeter radiometers in a geostationary precipitation mission.

Particular emphasis in this article was put on describing the algorithms for the data-analysis of submillimeter-wave cloud ice data (retrieval algorithms) and demonstrating their maturity.

Overall, the retrieval algorithms for CloudIce rest on a firm scientific basis, with the exception of the speculative class 4 products. On the other hand, coding the algorithms for operational processing, as well as doing thorough validation of the products, would still be considerable work. For this work aircraft data is very useful. Together with the two already available US instruments, the new international submillimeterwave airborne radiometer (ISMAR) will create excellent opportunities for scientific studies with campaign data, and for further algorithm validation and fine-tuning. ISMAR is currently under development by the Met Office (UK) with ESA co-funding.

Several approaches for CloudIce retrieval demonstration have already been followed. Pure simulation studies have demonstrated the retrieval algorithm for class 2 and class 3 data products. Studies with aircraft data have shown that the class 2 product retrieval algorithm works also with real millimeter/submillimeter data, and that the result is consistent with airborne radar measurements. Studies of operational millimeter-wave data near $183.31 \mathrm{GHz}$, combined with collocated CloudSat data, have demonstrated that IWP retrieval works with these data. (Of course the performance without the higher frequency channels is much poorer than CloudIce, but it is consistent with expectations.) Retrievals from submillimeter data from the Odin and MLS missions further 
demonstrate our capability to handle also submillimeter data correctly.

When all these approaches are taken together, they demonstrate that we have a robust understanding of the radiative properties of cloud ice in the millimeter/submillimeter spectral range, and that we have a proven toolbox of retrieval algorithms to work with these data.

Acknowledgements. We acknowledge the help of the CloudIce science community that has contributed in innumerable ways to the ideas presented in this article. Stefan Buehler's work was supported by the Swedish Space Board under the project "Satellite Atmospheric Science”. Salomon Eliasson's work was supported by the Swedish Research Council. The Observatory of Paris team was supported by CNES TOSCA. We further acknowledge that much of the work presented here has been supported by various ESA studies. Finally, we acknowledge the help of the ARTS radiative transfer community.

Edited by: J. Cermak

\section{References}

Anderson, G. P., Clough, S. A., Kneizys, F. X., Chetwynd, J. H., and Shettle, E. P.: AFGL atmospheric constituent profiles (0$120 \mathrm{~km}$ ), Tech. rep., AFGL TR-86-0110, AFGL, Cambridge, USA, 1986.

Atkinson, N. C.: Calibration, Monitoring and Validation of AMSUB, Adv. Space. Res., 28, 117-126, 2001.

Bauer, P., Lopez, P., Benedetti, A., Salmond, D., and Moreau, E.: Implementation of 1D+4D-Var Assimilation of Precipitation Affected Microwave Radiances at ECMWF, Part I: 1D-Var, Tech. rep., European Centre for Medium-Range Weather Forecasts ECMWF, Technical Memorandum, 2006a.

Bauer, P., Lopez, P., Salmond, D., Benedetti, A., Saarinen, S., and Bonazzola, M.: Implementation of 1D+4D-Var Assimilation of Precipitation Affected Microwave Radiances at ECMWF, Part II: 4D-Var, Tech. rep., European Centre for Medium-Range Weather Forecasts ECMWF, Technical Memorandum, ECMWF, Reading, UK, 2006b.

Bredow, J. W., Porco, R., Dawson, M. S., Betty, C. L., Self, S., and Thordarson, T.: A Multifrequency Laboratory Investigation of Attenuation and Scattering from Volcanic Ash Clouds, IEEE Geosci. Remote Sens., 33, 1071-1082, doi:10.1109/36.406693, 1995.

Buehler, S. A. and John, V. O.: A Simple Method to Relate Microwave Radiances to Upper Tropospheric Humidity, J. Geophys. Res., 110, D02110, doi:10.1029/2004JD005111, 2005.

Buehler, S. A., Eriksson, P., Kuhn, T., von Engeln, A., and Verdes, C.: ARTS, the atmospheric radiative transfer simulator, J. Quant. Spectrosc. Ra., 91, 65-93, doi:10.1016/j.jqsrt.2004.05.051, 2005.

Buehler, S. A., Courcoux, N., and John, V. O.: Radiative transfer calculations for a passive microwave satellite sensor: Comparing a fast model and a line-by-line model, J. Geophys. Res., 111, D20304, doi:10.1029/2005JD006552, 2006.
Buehler, S. A., Jiménez, C., Evans, K. F., Eriksson, P., Rydberg, B., Heymsfield, A. J., Stubenrauch, C., Lohmann, U., Emde, C., John, V. O., Sreerekha, T. R., and Davis, C. P.: A concept for a satellite mission to measure cloud ice water path and ice particle size, Q. J. Roy. Meteorol. Soc., 133, 109-128, doi:10.1002/qj.143, 2007.

Buehler, S. A., Kuvatov, M., John, V. O., Milz, M., Soden, B. J., Jackson, D. L., and Notholt, J.: An Upper Tropospheric Humidity Data Set From Operational Satellite Microwave Data, J. Geophys. Res., 113, D14110, doi:10.1029/2007JD009314, 2008.

Buehler, S. A., John, V. O., Kottayil, A., Milz, M., and Eriksson, P.: Efficient Radiative Transfer Simulations for a Broadband Infrared Radiometer - Combining a Weighted Mean of Representative Frequencies Approach with Frequency Selection by Simulated Annealing, J. Quant. Spectrosc. Ra., 111, 602-615, doi:10.1016/j.jqsrt.2009.10.018, 2010.

Buehler, S. A., Eriksson, P., and Lemke, O.: Absorption lookup tables in the radiative transfer model ARTS, J. Quant. Spectrosc. Ra., 112, 1559-1567, doi:10.1016/j.jqsrt.2011.03.008, 2011.

Chaboureau, J., Söhne, N., Pinty, J., Meirold-Mautner, I., Defer, E., Prigent, C., Pardo, J. R., Mech, M., and Crewell, S.: A midlatitude precipitating cloud database validated with satellite observations, J. Appl. Meteorol. Clim., 47, 1337-1353, 2008.

Charlton, J., Jarrett, M. L., Humphries, M. E., Child, R. K., Atkinson, N. L., Hewison, T. J., Slingo, A., Spilling, D. A. V., Higgins, J. M., Bray, M. A., Foster, P. R., and Matheson, D. N.: Study on Future Microwave and Millimetre-wave Radiometer Requirements and Concepts, Final Report, Tech. rep., ESTEC Contract No 14841/01/NL/MM, Sula Systems, Wotton-Under-Edge, UK, 2002.

Charlton, J., Moyna, B., Lee, C., and Defer, E.: Study of a Submillimetre Wave Airborne Demonstrator for Observations of Precipitation and Ice Clouds, Final Report, Tech. rep., ESTEC Contract No. 20927/07/NL/JA, Sula Systems, Wotton-Under-Edge, UK, 2010.

Davis, C., Emde, C., and Harwood, R.: A 3D Polarized Reversed Monte Carlo Radiative Transfer Model for mm and sub-mm Passive Remote Sensing in Cloudy Atmospheres, IEEE T. Geosci. Remote, 43, 1096-1101, doi:10.1109/TGRS.2004.837505, 2005.

Davis, C. P., Evans, K. F., Buehler, S. A., Wu, D. L., and Pumphrey, H. C.: 3-D polarised simulations of space-borne passive $\mathrm{mm} / \mathrm{sub}$ mm midlatitude cirrus observations: a case study, Atmos. Chem. Phys., 7, 4149-4158, doi:10.5194/acp-7-4149-2007, 2007.

Defer, E., Prigent, C., Aires, F., Pardo, J. R., Walden, C. J., Zanife, O. Z., Chaboureau, J. P., and Pinty, J. P.: Development of precipitation retrievals at millimeter and sub-millimeter wavelengths for geostationary satellites, J. Geophys. Res., 113, D08111, doi:10.1029/2007JD008673, 2008.

Delanoë, J. and Hogan, R. J.: A variational scheme for retrieving ice cloud properties from combined radar, lidar, and infrared radiometer, J. Geophys. Res., 113, D07204, doi:10.1029/2007JD009000, 2008.

Delene, D. J., Rose, W. I., and Grody, N. C.: Remote sensing of volcanic ash clouds using special sensor microwave imager data, J. Geophys. Res., 101, 11579-11588, 1996.

Desbois, M., Roca, R., Eymard, L., Viltard, N., Viollier, M., Srinivasan, J., and Narayanan, S.: The Megha-Tropiques mission, Proc. SPIE, 4899, 172-183, 2002. 
Eliasson, S., Buehler, S. A., Milz, M., Eriksson, P., and John, V. O.: Assessing observed and modelled spatial distributions of ice water path using satellite data, Atmos. Chem. Phys., 11, 375391, doi:10.5194/acp-11-375-2011, 2011.

Emde, C., Buehler, S. A., Davis, C., Eriksson, P., Sreerekha, T. R., and Teichmann, C.: A Polarized Discrete Ordinate Scattering Model for Simulations of Limb and Nadir Longwave Measurements in 1D/3D Spherical Atmospheres, J. Geophys. Res., 109, D24207, doi:10.1029/2004JD005140, 2004.

Eriksson, P., Rydberg, B., Johnston, M., Murtagh, D. P., Struthers, H., Ferrachat, S., and Lohmann, U.: Diurnal variations of humidity and ice water content in the tropical upper troposphere, Atmos. Chem. Phys., 10, 11519-11533, doi:10.5194/acp-1011519-2010, 2010.

Eriksson, P., Buehler, S. A., Davis, C. P., Emde, C., and Lemke, O.: ARTS, the atmospheric radiative transfer simulator, Version 2, J. Quant. Spectrosc. Ra., 112, 1551-1558, doi:10.1016/j.jqsrt.2011.03.001, 2011a.

Eriksson, P., Rydberg, B., and Buehler, S. A.: On cloud ice induced absorption and polarisation effects in microwave limb sounding, Atmos. Meas. Tech., 4, 1305-1318, doi:10.5194/amt-4-13052011, 2011 b.

Evans, K. F. and Stephens, G. L.: Microwave Radiative Transfer through Clouds Composed of Realistically Shaped Ice Crystals, Part II. Remote Sensing of Ice Clouds, J. Atmos. Sci., 52, 20582072, 1995.

Evans, K. F., Walter, S. J., Heymsfield, A. J., and Deeter, M. N.: Modeling of Submillimeter Passive Remote Sensing of Cirrus Clouds, J. Appl. Meteorol., 37, 184-205, 1998.

Evans, K. F., Wang, J. R., Racette, P. E., Heymsfield, G., and Li, L.: Ice cloud Retrievals and Analysis with Data from the Compact Scanning Submillimeter Imaging Radiometer and the Cloud Radar System during CRYSTAL-FACE, J. Appl. Meteorol., 44, 839-859, 2005.

Ferraro, R. R., Weng, F., Grody, N. C., Zhao, L., Meng, H., Kongoli, C., Pellegrino, P., Qiu, S., and Dean, C.: NOAA operational hydrological products derived from the advanced microwave sounding unit, IEEE T. Geosci. Remote, 43, 1036-1049, 2005.

Fischer, H., Birk, M., Blom, C., Carli, B., Carlotti, M., von Clarmann, T., Delbouille, L., Dudhia, A., Ehhalt, D., Endemann, M., Flaud, J. M., Gessner, R., Kleinert, A., Koopman, R., Langen, J., López-Puertas, M., Mosner, P., Nett, H., Oelhaf, H., Perron, G., Remedios, J., Ridolfi, M., Stiller, G., and Zander, R.: MIPAS: an instrument for atmospheric and climate research, Atmos. Chem. Phys., 8, 2151-2188, doi:10.5194/acp-8-2151-2008, 2008.

Golding, B. W. and Atkinson, N. C.: Study of Future Microwave Sounders on Geostationary and Medium Earth Orbits, Task 1 Report: Review of Preliminary List of Products and Corresponding Requirements, Tech. rep., ESA study STN/PR72/002, MGOMET-RP-001, Met Office, Exeter, UK, 2002.

Heymsfield, A. J., Protat, A., Austin, R., Bouniol, D., Hogan, R., Delanoë, J., Okamoto, H., Sato, K., van Zadelhoff, G.-J., Donovan, D., and Wang, Z.: Testing IWC Retrieval Methods Using Radar and Ancillary Measurements with In Situ Data, J. Appl. Meteorol. Clim., 47, 135-163, doi:10.1175/2007JAMC1606.1, 2008.

Hinsman, D.: Satellite Systems and Requirements, CEOS/WMO database, Version 2.5, Tech. rep., World Meteorological Organization, http://alto-stratus.wmo.ch/sat/stations/SatSystem.html (last access: May 2010), 2003.

Holl, G., Buehler, S. A., Rydberg, B., and Jiménez, C.: Collocating satellite-based radar and radiometer measurements - methodology and usage examples, Atmos. Meas. Tech., 3, 693-708, doi:10.5194/amt-3-693-2010, 2010.

Hong, G., Yang, P., Baum, B. A., Heymsfield, A. J., Weng, F., Liu, Q., Heygster, G., and Buehler, S. A.: Scattering Database in the Millimeter and Submillimeter Wave Range of $100-1000 \mathrm{GHz}$ for Nonspherical Ice Particles, J. Geophys. Res., 114, D06201, doi:10.1029/2008JD010451, 2009.

Jarret, M., Buehler, S., Child, R. K., Jiménez, C., Courcoux, N., Emde, C., Heygster, G., Sreerekha, T. R., Eriksson, P., Rydberg, B., Foster, P. R., Rose, T., Davis, C., Evans, K. F., Heymsfield, A., Lohmann, U., and Stubenrauch, C.: Establishment of Mission and Instrument Requirements to Observe Cirrus Clouds at SubMillimetre Wavelengths, Tech. rep., Final Report, ESTEC Contract No. 19053/05/NL/AR, Sula Systems, Wotton-Under-Edge, UK, 2007.

Jiménez, C., Buehler, S. A., Rydberg, B., Eriksson, P., and Evans, K. F.: Performance simulations for a submillimetre wave cloud ice satellite instrument, Q. J. Roy. Meteorol. Soc., 133, 129-149, doi:10.1002/qj.134, 2007.

John, V. O. and Buehler, S. A.: The impact of ozone lines on AMSU-B radiances, Geophys. Res. Lett., 31, L21108, doi:10.1029/2004GL021214, 2004.

Lambrigtsen, B. H.: Calibration of the AIRS Microwave Instruments, IEEE T. Geosci. Remote, 41, 369-378, 2003.

Manabe, T., Sato, K., and Ihara, T.: Measurement of Complex Refractive Index of Soda-Lime Glass at $60 \mathrm{GHz}$ by VectorNetwork-Analyser-Based Scatterometer, Elec. Lett., 28, 1354 1355, doi:10.1049/el:19920859, 1992.

Mech, M.: Information Content of Millimeter-Wave Observations for Hydrometeor Properties in Mid-Latitudes, IEEE T. Geosci. Remote, 45, 2287-2299, doi:10.1109/tgrs.2007.898261, 2007.

Meirold-Mautner, I.: Radiative Transfer Simulations Using Mesoscale Cloud Model Outputs: Comparisons with Passive Microwave and Infrared Satellite Observations for Midlatitudes, J. Atmos. Sci., 64, 1550-1568, doi:10.1175/JAS3896.1, 2007.

Miao, J., Johnsen, K.-P., Buehler, S., and Kokhanovsky, A.: The potential of polarization measurements from space at $\mathrm{mm}$ and sub$\mathrm{mm}$ wavelengths for determining cirrus cloud parameters, Atmos. Chem. Phys., 3, 39-48, doi:10.5194/acp-3-39-2003, 2003.

Mishchenko, M. I. and Travis, L. D.: Capabilities and limitations of a current FORTRAN implementation of the T-matrix method for randomly oriented rotationally symmetric scatterers, J. Quant. Spectrosc. Ra., 60, 309-324, 1998.

Mitchell, D. L., Rasch, P., Ivanova, D., McFarquhar, G., and Nousiainen, T.: Impact of small ice crystal assumptions on ice sedimentation rates in cirrus clouds and GCM simulations, Geophys. Res. Lett., 35, L09806, doi:10.1029/2008GL033552, 2008.

Nesbitt, S. W. and Zipser, E. J.: The diurnal cycle of rainfall and convective intensity according to three years of TRMM measurements, J. Climate, 16, 1456-1475, 2003.

Penner, J. E.: Climate change: The cloud conundrum, Nature, 432, 962-963, doi:10.1038/432962a, 2004.

Prigent, C., Pardo, J. R., Mishchenko, M. I., and Rossow, W. B.: Microwave polarized signatures generated within cloud systems: Special Sensor Microwave Imager (SSM/I) observations interpreted with radiative transfer simulations, J. Geophys. Res., 106, 
28243-28258, 2001.

Prigent, C., Defer, E., Pardo, J. R., Pearl, C., Rossow, W. B., and Pinty, J.-P.: Relations of polarized scattering signatures observed by the TRMM Microwave Instrument with electrical processes in cloud systems, Geophys. Res. Lett., 32, L04810, doi:10.1029/2004GL022225, 2005.

Rizzi, R., Bauer, P., Crewell, S., Leroy, M., Mätzler, C., Menzel, W. P., Ritter, B., Russell, J. E., and Thoss, A.: Cloud, Precipitation and Large Scale Land Surface Imaging (CPL) Observational Requirements for Meteorology, Hydrology and Climate, EUMETSAT position paper, EUMETSAT, Darmstadt, Germany, 2006.

Rydberg, B., Eriksson, P., and Buehler, S. A.: Prediction of cloud ice signatures in sub-mm emission spectra by means of groundbased radar and in-situ microphysical data, Q. J. Roy. Meteorol. Soc., 133, 151-162, doi:10.1002/qj.151, 2007.

Rydberg, B., Eriksson, P., Buehler, S. A., and Murtagh, D. P.: NonGaussian Bayesian retrieval of tropical upper tropospheric cloud ice and water vapour $\mathrm{f}$ rom Odin-SMR measurements, Atmos. Meas. Tech., 2, 621-637, doi:10.5194/amt-2-621-2009, 2009.

Saunders, R., Matricardi, M., and Brunel, P.: A fast radiative transfer model for assimilation of satellite radiance observation - RTTOV-5, Tech. rep., European Centre for Medium-Range Weather Forecasts ECMWF, Technical Memorandum, ECMWF, Reading, UK, 1999.

Solomon, S., Qin, D., Manning, M., Chen, Z., Marquis, M., Averyt, K. B., Tignor, M., and Miller, H. L. (Eds.): Climate Change 2007: The Physical Science Basis. Contribution of Working Group I to the Fourth Assessment Report of the Intergovernmental Panel on Climate Change, Cambridge University Press, 2007.

Sreerekha, T. R., Emde, C., Courcoux, N., Teichmann, C., Buehler, S. A., Loehnert, U., Mech, M., Crewell, S., Battaglia, A., Eriksson, P., Rydberg, B., Davis, C., Jiménez, C., English, S., and Doherty, A.: Development of an RT model for frequencies between 200 and $1000 \mathrm{GHz}$, Final Report, Tech. rep., ESTEC Contract No. 17632/03/NL/FF, University of Bremen, Bremen, Germany, 2006

Sreerekha, T. R., Buehler, S. A., O'Keeffe, U., Doherty, A., Emde, C., and John, V. O.: A strong ice cloud event as seen by a microwave satellite sensor: Simulations and Observations, J. Quant. Spectrosc. Ra., 109, 1705-1718, doi:10.1016/j.jqsrt.2007.12.023, 2008.

Stephens, G. L., Tsay, S., Stackhouse Jr., P. W., and Flatau, P. J.: The relevance of the microphysical and radiative properties of cirrus clouds to climate and climatic feedback, J. Atmos. Sci., 47, 1742-1753, 1990.

Stubenrauch, C.: Cirrus microphysical properties and their effect on Radiation: survey and integration into climate Models using combined Satellite observations, Tech. rep., Laboratoire de Meteorologie Dynamique, Meteorological Office, Institute for Marine Research at Kiel, Laboratoire d'Optique Atmospherique, final Report on the Environment project EVK2CT-2000-00063, available at: http://www.lmd.polytechnique.fr/ CIRAMOSA/Welcome.html, 2004.
Toon, O. B., Starr, D. O., Jensen, E. J., Newman, P. A., Platnick, S., Schoeberl, M. R., Wennberg, P. O., Wofsy, S. C., Kurylo, M. J., Maring, H., Jucks, K. W., Craig, M. S., Vasques, M. F., Pfister, L., Rosenlof, K. H., Selkirk, H. B., Colarco, P. R., Kawa, S. R., Mace, G. G., Minnis, P., and Pickering, K. E.: Planning, implementation, and first results of the Tropical Composition, Cloud and Climate Coupling Experiment (TC4), J. Geophys. Res., 115, D00J04, doi:10.1029/2009JD013073, 2010.

Waliser, D. E., Li, J.-L. F., Woods, C. P., Austin, R. T., Bacmeister, J., Chern, J., Genio, A. D., Jiang, J. H., Kuang, Z., Meng, H., Minnis, P., Platnick, S., Rossow, W. B., Stephens, G. L., SunMack, S., Tao, W.-K., Tompkins, A. M., Vane, D. G., Walker, C., and Wu, D.: Cloud ice: A climate model challenge with signs and expectations of progress, J. Geophys. Res., 114, D00A21, doi:10.1029/2008JD010015, 2009.

Waliser, D. E., Li, J.-L. F., L'Ecuyer, T. S., and Chen, W.-T.: The impact of precipitating ice and snow on the radiation balance in global climate models, Geophys. Res. Lett., 38, L06802, doi:10.1029/2010GL046478, 2011.

Wendisch, M., Pilewskie, P., Pommier, J., Howard, S., Yang, P., Heymsfield, A. J., Schmitt, C. G., Baumgardner, D., and Mayer, B.: Impact of cirrus crystal shape on solar spectral irradiance: a case study for subtropical cirrus, J. Geophys. Res., 110, D03202, doi:10.1029/2004JD005294, 2005.

WMO: Systematic Observation Requirements For Satellite-Based Products For Climate, vol. GCOS-107, WMO/TD No. 1338, WMO, 2006.

Wu, D. L., Jiang, J. H., Read, W. G., Austin, R. T., Davis, C. P., Lambert, A., Stephens, G. L., Vane, D. G., and Waters, J. W.: Validation of the Aurs MLS cloud ice water content measurements, J. Geophys. Res., 113, D15S10, doi:10.1029/2007JD008931, 2008.

Wu, D. L., Austin, R. T., Deng, M., Durden, S. L., Heymsfield, A. J., Jiang, J. H., Lambert, A., Li, J.-L., Livesey, N. J., McFarquhar, G. M., Pittman, J. V., Stephens, G. L., Tanelli, S., Vane, D. G., and Waliser, D. E.: Comparisons of global cloud ice from MLS, CloudSat, and correlative data sets, J. Geophys. Res., 114 D00A24, doi:10.1029/2008JD009946, 2009.

Zanifé, O.-Z., Prigent, C., Defer, E., Meirold-Mautner, I., Aires, F., and Walden, C.: Study of the Potential of Sub-Millimetre Wave Observations for Precipitation Retrieval, Final Report, Tech. rep., ESTEC contract No. 18054/04/NL/FF, CLS, Ramonville SaintAgne, France, 2007.

Zhao, L. and Weng, F.: Retrieval of Ice Cloud Parameters Using the Advanced Microwave Sounding Unit, J. Appl. Meteorol., 41, 384-395, 2002. 